NCCN

\section{Adolescent and Young Adult Oncology, Version 2.2018}

\section{Clinical Practice Guidelines in Oncology}

Peter F. Coccia, MD; Alberto S. Pappo, MD;

Lynda Beaupin, MD; Virginia F. Borges, MD, MMSc;

Scott C. Borinstein, MD, PhD; Rashmi Chugh, MD;

Shira Dinner, MD; Jeanelle Folbrecht, PhD;

A. Lindsay Frazier, MD, ScM; Robert Goldsby, MD;

Alexandra Gubin, MSW, LCSW-C; Robert Hayashi, MD;

Mary S. Huang, MD; Michael P. Link, MD;

John A. Livingston, MD; Yousif Matloub, MD;
Frederick Millard, MD; Kevin C. Oeffinger, MD;

Diane Puccetti, MD; Damon Reed, MD;

Steven Robinson, MBBS; Abby R. Rosenberg, MD, MS;

Tara Sanft, MD; Holly L. Spraker-Perlman, MD, MS;

Margaret von Mehren, MD; Daniel S. Wechsler, MD, PhD;

Kimberly F. Whelan, MD; Nicholas Yeager, MD;

Lisa A. Gurski, PhD; and Dorothy A. Shead, MS

\section{Overview}

Over the past 20 years, advances in cancer treatment have significantly improved survival rates for young children and older adults, but these improvements have generally not applied to adolescent and young adult (AYA) patients. ${ }^{1,2}$ One of the main reasons for the lack of improvement in outcomes is that AYA patients have a low rate of participation in clinical

\section{Please Note}

The NCCN Clinical Practice Guidelines in Oncology (NCCN Guidelines ${ }^{\circledR}$ ) are a statement of consensus of the authors regarding their views of currently accepted approaches to treatment. Any clinician seeking to apply or consult the NCCN Guidelines ${ }^{\circledR}$ is expected to use independent medical judgment in the context of individual clinical circumstances to determine any patient's care or treatment. The National Comprehensive Cancer Network $^{\circledR}\left(\mathrm{NCCN}^{\circledR}\right)$ makes no representation or warranties of any kind regarding their content, use, or application and disclaims any responsibility for their applications or use in any way. The full NCCN Guidelines for Adolescent and Young Adult Oncology are not printed in this issue of JNCCN but can be accessed online at NCCN.org.

(C) National Comprehensive Cancer Network, Inc. 2018, All rights reserved. The NCCN Guidelines and the illustrations herein may not be reproduced in any form without the express written permission of NCCN.

\section{Disclosures for the NCCN Adolescent and Young Adult Oncology Panel}

At the beginning of each NCCN Guidelines panel meeting, panel members review all potential conflicts of interest. NCCN, in keeping with its commitment to public transparency, publishes these disclosures for panel members, staff, and NCCN itself.

Individual disclosures for the NCCN Adolescent and Young Adult Oncology Panel members can be found on page 97. (The most recent version of these guidelines and accompanying disclosures are available on the NCCN Web site at NCCN.org.)

These guidelines are also available on the Internet. For the latest update, visit NCCN.org. 


\section{Journal of the National Comprehensive Cancer Network}

trials. ${ }^{1,3-6}$ In the United States, approximately $10 \%$ of patients 15 to 19 years of age and $1 \%$ to $2 \%$ of patients 20 to 39 years of age are enrolled in clinical trials. ${ }^{7}$ In addition to the low rate of participation in clinical trials, several other factors contribute to the poor outcome in AYA patients, such as differences in disease biology, lack of consistency in treatment approaches, poor adherence or intolerance to therapy, lack of health insurance, delays in diagnosis, and physician's lack of familiarity with cancer in the AYA population. ${ }^{8}$ AYA patients also face unique developmental and psychosocial issues that make adjustment to their disease, health-maintenance, and financial hardships more challenging., ${ }^{6,-12}$

The biology, epidemiology, and clinical outcomes affecting AYA patients are usually different than those of younger and older patients with cancer. ${ }^{13,14}$ In addition, the genetic, physiologic, and pharmacologic changes as- sociated with AYA patients may impact their ability to tolerate cancer therapy and their response to treatment. Moreover, short- and long-term toxicities impacting a young, independent patientincluding the impact of treatment on fertilitymay disincentivize treatment, leading to gaps in adherence and poor outcomes. Attention to these issues and providing options that empower the patient at the time of initial cancer treatment may result in more successful implementation of the planned therapy. Unlike comprehensive geriatric assessment, which is helpful to physicians in developing a coordinated treatment plan and understanding the functional needs of older patients, no similar assessment has been reported for AYA patients. There are less evidence-based data to guide the treatment of AYA patients. AYA

Text cont. on page 77 .

\section{NCCN Adolescent and Young Adult Oncology Panel Members}

\footnotetext{
*Peter F. Coccia, MD/Chair $€ \neq \xi$ Fred \& Pamela Buffett Cancer Center

*Alberto S. Pappo, MD/Vice Chair€‡ St. Jude Children's Research Hospital/ The University of Tennessee Health Science Center * Lynda Beaupin, MD€ Roswell Park Cancer Institute

Virginia F. Borges, MD, MMSct University of Colorado Cancer Center

* Scott C. Borinstein, MD, PhD€‡ Vanderbilt-Ingram Cancer Center

Rashmi Chugh, MD‡† University of Michigan Comprehensive Cancer Center Shira Dinner, MD† $\ddagger$ Robert H. Lurie Comprehensive Cancer Center of Northwestern University

Jeanelle Folbrecht, PhD $\theta f$ City of Hope Comprehensive Cancer Center

A. Lindsay Frazier, MD, ScM€‡ Dana-Farber/Brigham and Women's Cancer Center Robert Goldsby, MD€ UCSF Helen Diller Family Comprehensive Cancer Center

*Alexandra Gubin, MSW, LCSW-Cf The Sidney Kimmel Comprehensive Cancer Center at Johns Hopkins

*Robert Hayashi, MD€¥ $\xi$ Siteman Cancer Center at Barnes-Jewish Hospital and Washington University School of Medicine

Mary S. Huang, MD€‡ Massachusetts General Hospital Cancer Center Michael P. Link, MD€ Stanford Cancer Institute

John A. Livingston, MD†‡ The University of Texas MD Anderson Cancer Center Yousif Matloub, MD€ Case Comprehensive Cancer Center/ University Hospitals Seidman Cancer Center and Cleveland Clinic Taussig Cancer Center
}

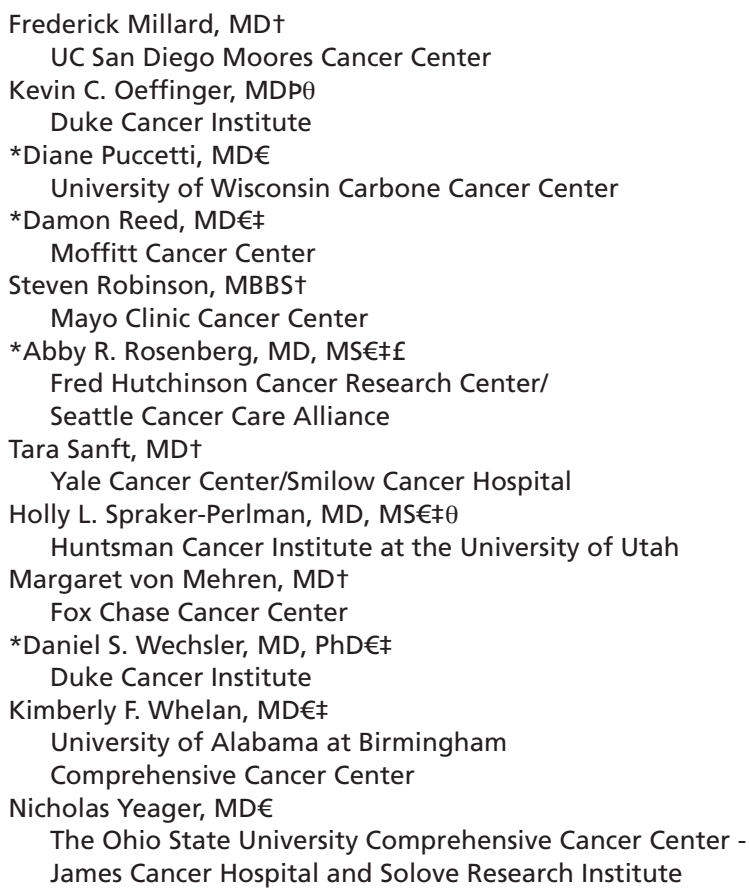

NCCN Staff: Lisa A. Gurski, PhD, and Dorothy A. Shead, MS

KEY

*Discussion Section Writing Committee

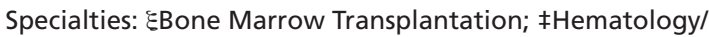
Hematology Oncology; PInternal Medicine; †Medical Oncology $€$ Pediatric Oncology; $\theta$ Psychiatry and Psychology, Including Health Behavior; fSupportive Care Including Palliative, Pain Management, Pastoral Care, and Oncology Social Work 


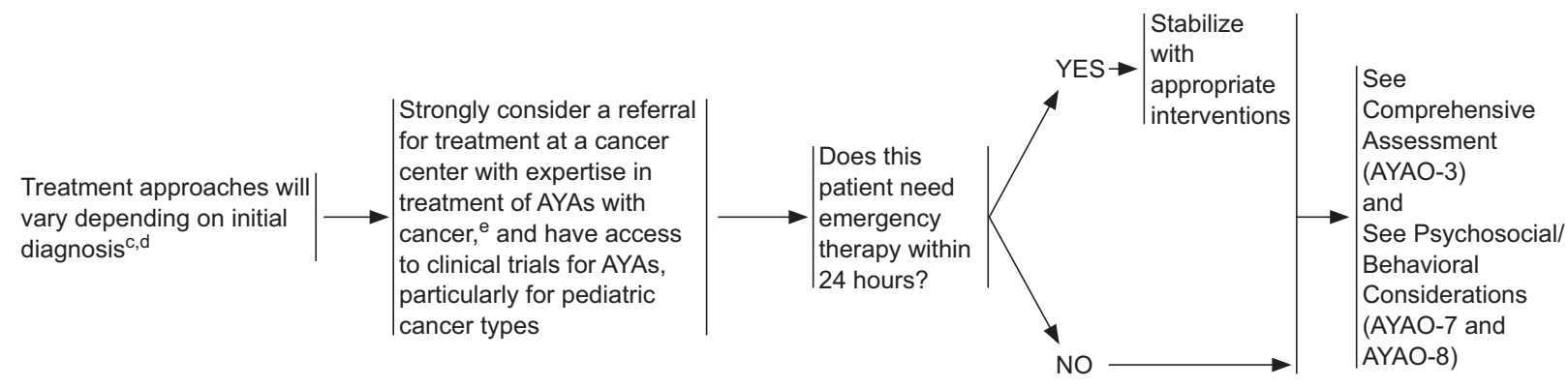

${ }^{*}$ Available online, in these guidelines, at NCCN.org.

'See Age-Specific SEER Incidences of Cancer by Age Group and Sex in the AYA Population (2008-2012) (AYAO-4*).

dSee Definition of AYA Population (AYAO-1*).

eThese centers provide a multidisciplinary approach involving a team of providers with expertise in cancer treatment and management of specific mental health and developmental issues such as fertility, education, career development, employment, family planning, pregnancy, sexually transmitted diseases, smoking, and substance abuse.

AYAO-2

Clinical trials: NCCN believes that the best management of any patient with cancer is in a clinical trial. Participation in clinical trials is especially encouraged. All recommendations are category $2 \mathrm{~A}$ unless otherwise indicated.

(C) JNCCN_Journal of the National Comprehensive Cancer Network | Volume 16 Number 1 | January 2018 


\section{COMPREHENSIVE ASSESSMENT}

- Provide age-appropriate information related to cancer

See Online Resources for AYA Patients and Survivors (AYAO-D*)

- All women of child-bearing potential must receive a pregnancy test prior to initiating therapy

- Discuss contraception prior to initiating therapy

- Discuss risks of infertility due to cancer and its therapy, as well as options for fertility preservation

See Fertility/Endocrine Considerations (AYAO-6)

- Psychosocial assessment

- See Psychosocial/Behavioral Considerations

$\checkmark$ Individual (AYAO-7 and AYAO-8)

$\checkmark$ Relationships (AYAO-9)

$\checkmark$ Socioeconomic Issues (AYAO-10)

- See NCCN Guidelines for Distress Management†

- Recommend referral for genetic and familial risk assessment/counseling as appropriate based on clinical/family history and histologic diagnosis

- Risk factors for breast cancer

$\diamond$ Germline mutations of BRCA1, BRCA2, TP53 (Li-Fraumeni syndrome), or PTEN (Cowden syndrome)

See NCCN Guidelines for Genetic/Familial High-Risk Assessment: Breast and Ovarian†

$\diamond$ Chest irradiation

- Risk factors for colon cancer

$\checkmark$ Mutations in MMR genes [hereditary nonpolyposis colorectal cancer (HNPCC or Lynch syndrome)] or APC genes [familial adenomatous polyposis (FAP)]

See NCCN Guidelines for Colorectal Cancer Screening $\dagger$

- Risk factors for sarcomas See NCCN Guidelines for Soft Tissue Sarcoma $\dagger$

$\diamond$ Li-Fraumeni syndrome

$\diamond$ Germline mutations in the retinoblastoma $(R b)$ gene or succinate dehydrogenase $(S D H)$ gene. Testing for germline mutations in the SDH subunit genes should be considered for AYAs with wild-type gastrointestinal stromal tumors (GIST) (lacking KIT or PDGFRA mutations) or paragangliomas

$\checkmark$ FAP-associated desmoid tumors (aggressive fibromatosis) See NCCN Guidelines for Colorectal Cancer Screening $\dagger$

$\checkmark$ Germline mutations in neurofibromatosis-1 (NF-1) gene are associated with malignant peripheral nerve sheath tumor (MPNST)

- Risk Factors for Multiple Endocrine Neoplasms (MEN)

$\diamond$ See NCCN Guidelines for Neuroendocrine Tumors $\dagger$

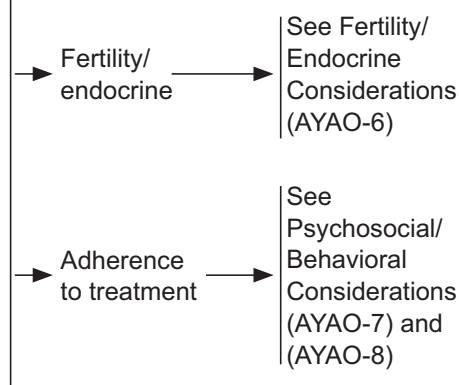

${ }^{*}$ Available online, in these guidelines, at NCCN.org.

$\dagger$ Available at NCCN.org. 
TREATMENT-RELATED ISSUES

Dose schedules $\longrightarrow \begin{aligned} & \cdot \text { Selected AYA patients may tolerate more intensive therapies than older patients } \\ & \text { Dose intensity and dose density are associated with improved outcomes } \\ & \text { - See NCCN Guidelines for Myeloid Growth Factors } \dagger \text { for growth factor support } \\ & \text { Dose reductions are often based upon avoiding severe, irreversible organ damage } \\ & \text { Assume that the patient population has a significant long-term survival and that significant end-organ } \\ & \text { damage may compromise long-term function and quality of life } \\ & \text { Monitoring of cumulative dosing and schedule for certain medications associated with irreversible organ } \\ & \text { damage and fertility issues may be essential when certain lifetime exposure is encountered. See AYAO-11* } \\ & \text { for specific agents } \\ & \text { Maximum cumulative dosing parameters are often established for a patient to reduce the risk of significant } \\ & \text { irreversible damage }\end{aligned}$

Toxicities

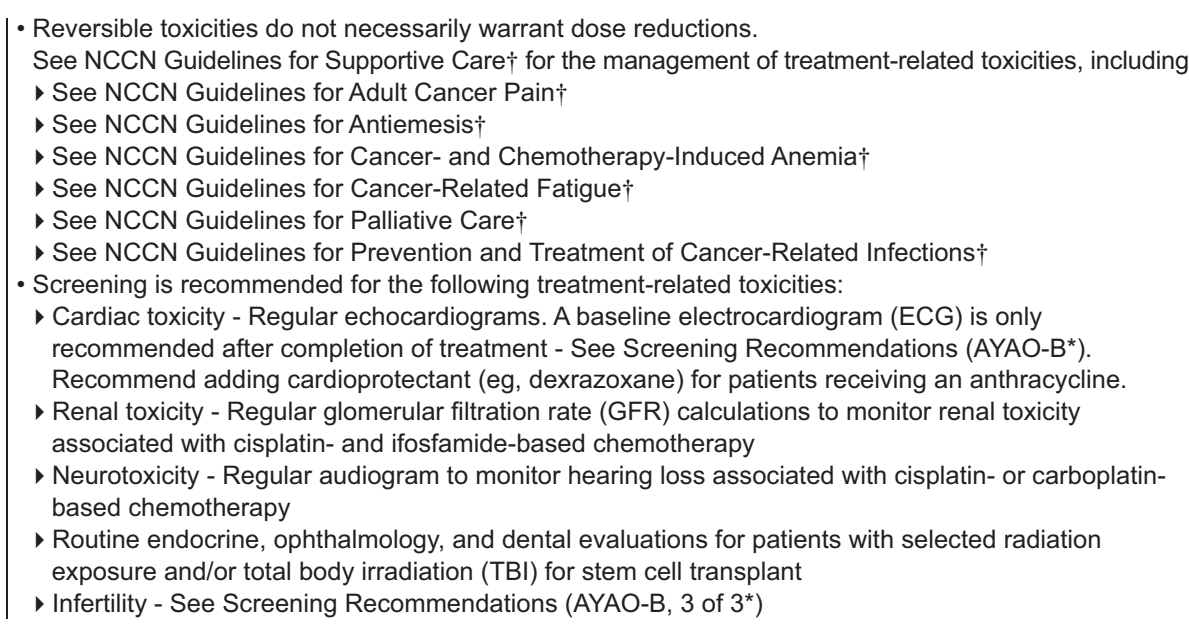

*Available online, in these guidelines, at NCCN.org.

$\dagger$ Available at NCCN.org.

hWomer RB, West DC, Krailo MD, et al. J Clin Oncol 2012;30:4148-4154. DeAngelo DJ, Stevenson KE, Dahlberg SE, et al. Leukemia 2015;29:526-534.

Gerber NK, Wexler LH, Singer S, et al. Int J Radiat Oncol Biol Phys 2013;86:58-63.

AYAO-5

Clinical trials: NCCN believes that the best management of any patient with cancer is in a clinical trial. Participation in clinical trials is especially encouraged. All recommendations are category $2 \mathrm{~A}$ unless otherwise indicated.

(C) JNCCN_Journal of the National Comprehensive Cancer Network | Volume 16 Number 1 | January 2018 


\section{Adolescent and Young Adult Oncology, Version 2.2018}

\section{FERTILITY/ENDOCRINE CONSIDERATIONS}

- Fertility preservation as well as sexual health and function should be an essential part in the management of AYAs with cancer who are at any risk for infertility due to cancer treatments ${ }^{i}$

- Discuss risks for infertility due to cancer and its therapy (especially for high-risk therapies such as alkylating agents or gonadal irradiation), fertility preservation, and contraception prior to the start of therapy $^{\mathrm{j}}$

- Men are at risk for azoospermia following therapy, which may or may not resolve over time

- Women are at risk for premature ovarian failure following therapy
- Initiate referral for fertility preservation clinics within 24 hours for all patients who choose the option of fertility preservation

$\rightarrow$ - Refer to a mental health professional to assist with complex decision making if needed. See Psychosocial/ Behavioral Considerations (AYAO-7 and AYAO-8)
Males

- Discuss the option of sperm banking

- Suggest a local sperm bank, or available online sperm banking kit

- Consider follow-up with fertility specialist posttreatment

Females

- Discuss the option of embryo or oocyte

cryopreservation or ovarian tissue cryopreservation (if available)

- Initiate if provider deems that therapy can be delayed long enough for a cycle of oocyte stimulation (for low- and intermediate-risk Hodgkin's lymphoma, low-grade sarcomas, and breast cancer)

- Consider follow-up with fertility specialist post-

treatment

- Oophoropexy

- Ovaries may be surgically moved away from the planned radiation field, either during cancer surgery or in a separate procedure

- Menstrual suppression

- Medroxyprogesterone, oral contraceptives, or gonadotropin-releasing hormone $(\mathrm{GnRH})$ agonists may be used in protocols that are predicted to cause prolonged thrombocytopenia and present a risk for menorrhagia

- It is controversial whether menstrual suppression would protect the ovaries, but some data suggest that menstrual suppression with $\mathrm{GnRH}$ agonists may protect ovaries in young women with breast cancer before the initiation of chemotherapy ${ }^{k}$

'Levine J, Canada A, Stern CJ. Fertility preservation in adolescents and young adults with cancer. J Clin Oncol 2010;28:4831-4841.

jThe impact of cancer therapy on fertility is related to the age of the patient at the time of treatment and is dependent on the duration, dose intensity, and type of treatment. See NCCN Guidelines for Breast Cancer for the management of women with breast cancer during pregnancy (available at NCCN.org).

kMoore HC, Unger JM, Phillips KA, et al. Goserelin for ovarian protection during breast-cancer adjuvant chemotherapy. N Engl J Med 2015;372:923-932.

Demeestere I, Brice P, Peccatori FA, et al. No evidence for the benefit of gonadotropin-releasing hormone agonist in preserving ovarian function and fertility in lymphoma survivors treated with chemotherapy: final long-term report of a prospective randomized trial. J Clin Oncol 2016;34:2568-2574. 
PSYCHOSOCIAL CONSIDERATIONS: INDIVIDUAL EVALUATION

\section{SUPPORTIVE CARE SERVICES/INTERVENTIONS}

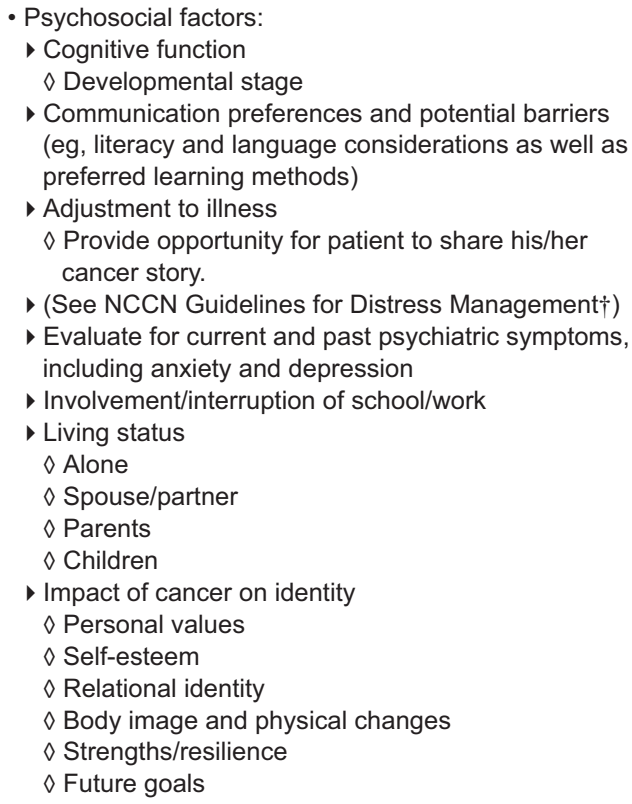

- Refer AYA patients with cognitive dysfunction or other psychiatric symptoms (eg, depression, anxiety) to a mental health provider and community-based resources serving AYA patients

- Offer psychosocial support and counseling to help alleviate distress (See NCCN Guidelines for Distress Management $\dagger$ ).

- Consider flexible treatment dates, consultation times, and procedures (evenings/weekends)

- For all AYA patients, provide counseling around decision-making regarding the risks of treatment-related infertility and discuss options for fertility preservation prior to the start of therapy. See Fertility/Endocrine Considerations (AYAO-6)

$\dagger$ Available at NCCN.org. 


\section{Adolescent and Young Adult Oncology, Version 2.2018}

BEHAVIORAL CONSIDERATIONS: INDIVIDUAL EVALUATION

- Behavioral factors:

- Adherence to therapy

- Tobacco, alcohol, cannabis, or other substance use/ abuse

- Sexual behavior/risks/concerns

- Assess nutritional requirements and potential deficits based on age

- Exercise needs, hobbies, and recreational activities - Sleep patterns

- Use of both integrative therapies and complementary and alternative medicine (CAM)

- Existential/spiritual issues

\section{SUPPORTIVE CARE SERVICES/INTERVENTIONS}

- Adherence to therapy

- Educate about the expectations of treatment and explain the patient's responsibility to adhere to therapy

- Provide education and/or guidance about each medication prior to the start of treatment and every time there is a change in treatment.

- Review list of medications and their dose, purpose, and adverse effects.Simplify dosing schedule and change timing and frequency of medication or method of administration, when medically possible, to fit into AYAs' lifestyle and normal activities

- Provide access to systematic and standardized symptom management for side effects related to cancer treatment. See NCCN Guidelines for Supportive Care $\dagger$

- Refer to smoking cessation program if needed. See NCCN Guidelines for Smoking Cessation $\dagger$

- Provide education about the impact of early cannabis use on cognitive development and mental health

- If AYA chooses to continue use, provide education on risks and benefits of varying methods of ingestion and dosing

- Refer patients with signs, symptoms, and a history of substance abuse or addiction to a risk reduction or substance abuse management program

- Provide education about the impact of treatment on sexual health including safe sexual practices in light of risk of infection, risk for bleeding, prevention of pregnancy, and sexually transmitted diseases See WHO recommendations in the Discussion section

- Provide education about potential diet/nutritional changes associated with cancer treatment and possible interventions. Refer to registered dietitian-certified specialist in oncology (RD-CSO)

- Refer to reputable providers of integrative therapies and CAM services.

- Refer patients experiencing challenges with their faith or belief in a just or fair world to faith-based resources or activities (eg, church youth groups, mentors). If necessary, refer to a chaplain or pastoral counselor

\footnotetext{
Relationships

See AYAO-9

Socioeconomic issues

See AYAO-10
}

$\dagger$ Available at NCCN.org. 
PSYCHOSOCIAL/BEHAVIORAL CONSIDERATIONS: RELATIONSHIPS EVALUATION

SUPPORTIVE CARE SERVICES/INTERVENTIONS

- Family status

- Interaction and relationship with parents

- Interaction and relationship with spouse/ partner

- Interaction and relationship with sibling(s)

- Patient with young children

- Peer relationships

- Sexual orientation

- Participation in community and social activities (eg, religious organizations, clubs, athletics/ recreation, music, youth groups)

- Communications with health care professionals - Decision-making preferences: family, friend, clinical care team, and/or self

- Information and communication preferences (eg, visual, auditory)

- Consider role of cultural and/or family values
- Promote communication between AYA patients and family members:

- Parents

- Spouse/partners

- Siblings

- Provide family members and partners with information about psychosocial support and behavioral services.

- Increase awareness of the possible psychosocial issues associated with cancer diagnosis in AYAs, so that family members and partners may continue to support the patient.

- Consider the following family-based intervention models from pediatric studies, which may have utility for AYAs:

- Parent support groups

- AYA support groups

- Social and recreational programs

- Psychoeducational programs

- Provide information about peer support to assist AYAs establishing and maintaining relationships with their peers as well as with other AYAs with cancer. See Online Resources for AYA Patients and Survivors (AYAO-D*)

- Face-to-face meetings

- Camp and retreat programs

- Online support groups

- Social networking opportunities

- Create flexible visiting hours and an environment that will encourage peers to visit AYA patients.

- Communicate directly with individual patients.

- Ask for permission to share information with family members.

- Provide developmentally appropriate information about their cancer, treatment options, and potential side effects. See Online Resources for AYA Patients and Survivors (AYAO-D*)

- Encourage completion of a medical power of attorney when appropriate.

*Available online, in these guidelines, at NCCN.org. 
PSYCHOSOCIAL/BEHAVIORAL CONSIDERATIONS: SOCIOECONOMIC ISSUES

EVALUATION

SUPPORTIVE CARE SERVICES/INTERVENTIONS

- Insurance availability and security

- Employer-provided

- Parent's insurance

- Health insurance marketplace

- Assessment of risk for losing

insurance

- Loss of employment

- Age out of parents' insurance

- Risk for financial loss or

bankruptcy

- Child care

- Transportation

- Accommodation if traveling to

receive treatment

- Stability of housing and basic

household socioeconomic needs

- Link qualified AYA patients to Medicaid, social security, and/or disability insurance

- Educate AYA patients about benefits they may qualify for, such as short- or long-term

disability, state disability benefits, and public assistance

- Provide information on obtaining financial assistance with fertility needs. Local and

institutional grants may be available

- Refer for career counseling and/or education support as indicated.

- Direct AYA patients to legal resources/advocates for understanding health insurance

coverage

- Identify resources for respite care for AYA patients with young children.

- Refer to transportation assistance programs (eg, van ride programs, voucher programs)

- Provide AYAs with a list of recommended and reliable online sources to access information

related to their cancer. See Online Resources for AYA Patients and Survivors (AYAO-D*)

- Financial assistance for AYA cancer survivors needs to be integrated into survivorship plans.

- AYAs with cancer need long-term follow-up care for monitoring and treatment of late effects

long after completion of treatment

${ }^{*}$ Available online, in these guidelines, at NCCN.org. 


\section{PALLIATIVE CARE and END-OF-LIFE CONSIDERATIONS}

Palliative care focuses on symptom control, reduction of physical suffering or discomfort, and optimizing quality of life at any stage of a life-threatening disease (see NCCN Guidelines for Palliative Care, available at NCCN.org). Referral to palliative care is appropriate when patients are being treated with curative intent and can be initiated at the time of initial diagnosis. ${ }^{1} \mathrm{~A}$ palliative care team is multidisciplinary, with resources and expertise to address the psychosocial, emotional, and physical challenges relevant to the patient. ${ }^{2}$ Strategies to support a patient, particularly in the AYA population, must be individualized in context of the family dynamic, including maturity of the patient and level of independence (both desired and actual).

\section{End-of-life considerations}

- Palliation of symptoms is an important aspect of end-of-life care.

- It is imperative for health care professionals not to assume that AYA patients may be less inclined to discuss death and other end-of-life issues. ${ }^{2}$

- Discussion about end-of-life preferences should begin early in treatment, but details should be individualized according to the preferences of the AYA patient and family. ${ }^{3}$

- Many adolescents indicate a preference for dying at home, yet $80 \%$ die in hospitals. ${ }^{4,5}$

- Physicians with experience in end-of-life care should facilitate discussion about issues such as nutrition/hydration, sedation treatment cessation, and place of death. ${ }^{2}$

- An advance care planning document is recommended for terminally ill AYA patients with metastatic cancer. ${ }^{3,6}$

- Ongoing psychosocial support is extremely important during the transition to end-of-life care. For family and friends, grief from loss may begin before death.

\footnotetext{
1Pritchard S, Cuvelier G, Harlos M, Barr R. Palliative care in adolescents and young adults with cancer. Cancer 2011;117:2323-2328.

2Wein S, Pery S, Zer A. Role of palliative care in adolescent and young adult oncology. J Clin Oncol 2010;28:4819-4824.

3Wiener L, Zadeh S, Wexler LH, Pao M. When silence is not golden: Engaging adolescents and young adults in discussions around end-of-life care choices. Pediatric Blood \& Cancer 2013;60:715-718.

4Bell CJ, Skiles J, Pradhan K, Champion VL. End-of-life experiences in adolescents dying with cancer. Support Care Cancer 2010;18:827-835.

5Webb NM, Tucker D. Young adults' opinions about hospice and home death. J Palliat Med 2009;12:337-342.

${ }^{6}$ Wiener L, Ballard E, Brennan T, et al. How I wish to be remembered: the use of an advance care planning document in adolescent and young adult populations. J Palliat Med 2008;11:1309-1313.
} 
patients diagnosed with cancer should be recognized as a distinct age group that has unique medical and psychosocial needs. ${ }^{15}$ The distinct biology of disease and age-related issues in AYA patients should be considered in the treatment decision-making process. ${ }^{16}$

The AYA patient is generally defined as an individual 15 to 39 years of age at the time of initial cancer diagnosis. ${ }^{6,17}$ Nearly 70,000 people in this age group are diagnosed with cancer each year in the United States, which is more than 7 times more people than are diagnosed at younger than 15 years of age. ${ }^{17}$ Compared with children younger than 15 years, 5-year relative survival in AYA patients is worse for those with acute lymphoblastic leukemia, acute myeloid leukemia (AML), Hodgkin lymphoma (HL), non-Hodgkin's lymphoma (NHL), astrocytomas, Ewing sarcoma, rhabdomyosarcoma, or osteosarcoma. ${ }^{18}$ Additionally, for Ewing sarcoma, outcomes are worse for patients $\geq 18$ years of age compared with patients $<18$ years. ${ }^{19-21}$ Conversely, 5-year relative survival is better in AYA patients with medulloblastomas and germ-cell tumors compared with in children with these tumors, possibly reflecting biologic differences in the tumors of each age group. Compared with adults 40 years and older, AYA patients tend to have better survival rates, except for those with breast and prostate cancer. ${ }^{18}$ Increasing age is associated with poorer prognosis in AYA patients with AML, NHL, Burkitt and Burkitt-like lymphoma, or rhabdomyosarcoma. ${ }^{22}$ Female AYA patients tend to have better 5 -year relative survival compared with male AYA patients. ${ }^{18}$

The spectrum of cancer types that affect the AYA population is unique and different from the types that affect the pediatric and older population. Cancer is the leading cause of death among the AYA population, excluding homicide, suicide, or unintentional injury. ${ }^{8,23}$ Lymphomas, melanoma, testicular cancer, female genital tract malignancies, thyroid cancer, bone and soft tissue sarcomas, leukemias, central nervous system (CNS) cancers, breast cancer, and non-gonadal germ cell tumors account for $95 \%$ of the cancers in this age group. ${ }^{1,24}$ The frequency and incidence of distribution of cancer types is also dramatically different across the age spectrum of AYA patients (see Table 1).

Quality care for AYA patients with cancer is tied to timely detection and start of treatment, adherence to treatment, and access to a multidisciplinary

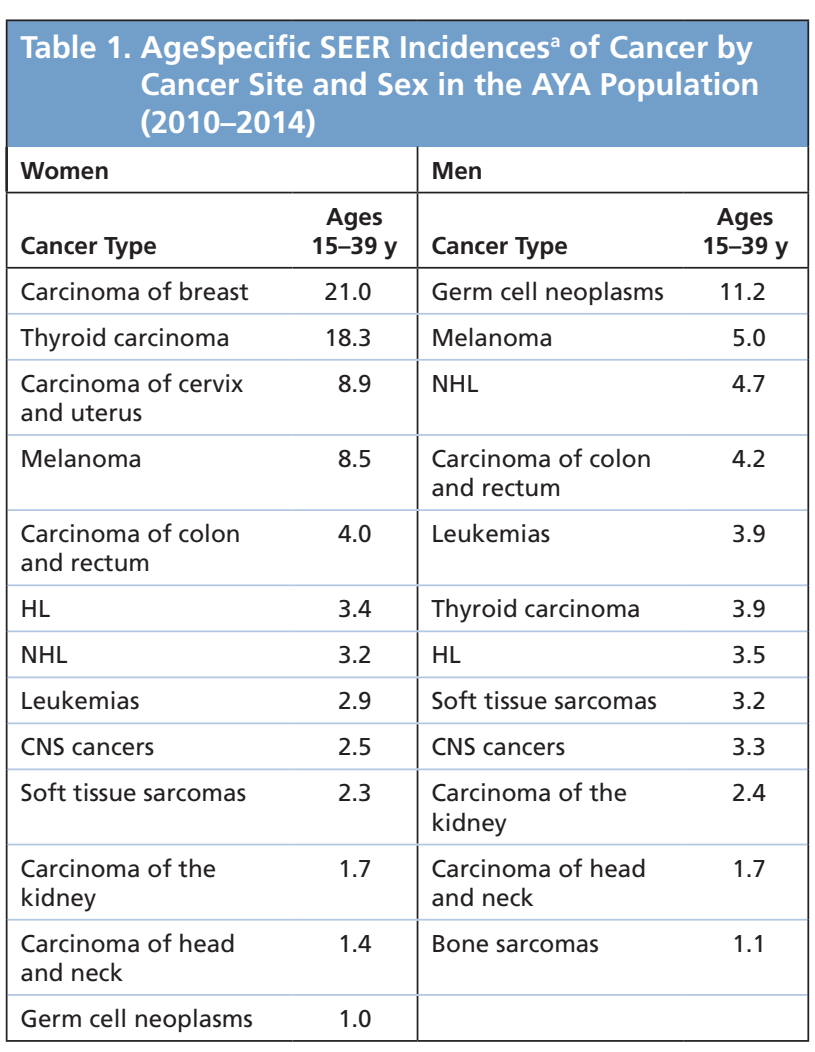

Abbreviations: CNS, central nervous system; HL, Hodgkin lymphoma; NHL, non-Hodgkin's lymphoma.

alncidence rates per 100,000.

Data from Howlader N, Noone AM, Krapcho M, et al, eds. SEER Cancer Statistics Review, 19752014, National Cancer Institute. Bethesda, MD. Available at: https://seer.cancer.gov/csr/1975_2014/, based on November 2016 SEER data submission, posted to the SEER website, April 2017.

team of healthcare professionals who are well-versed in the specific developmental issues relevant to this patient population. ${ }^{25,26}$ These issues include fertility, long-term side effects, psychosocial and socioeconomic issues, transportation to clinic appointments, maintaining school and work obligations, child care, treatment adherence, and the unique biology of disease. The relative importance of these issues varies considerably across the broad age range defined as AYA. Certain institutions have established centers specialized in accommodating the specific needs of AYA patients. A retrospective population-based analysis in California found that although the percentage of AYA patients who received care from a specialized cancer center increased over the past 20 years (27\% in 1991 to $43 \%$ in 2014), a minority of AYA patients receive care at specialized cancer centers. ${ }^{27}$ Referral of patients to AYA centers of excellence should be considered if feasible. 
The goals of the NCCN Guidelines for Adolescent and Young Adult Oncology are to identify issues specific to AYA patients and recommend interventions unique to these patients; educate physicians regarding the prevalence of cancer in the AYA population and its long-term consequences; and identify special considerations related to the management of cancer in AYA patients with the aim of improving treatment tolerance, adherence, and clinical outcomes; and to promote participation in clinical trials and enrollment on tumor banking and biologic protocols.

\section{Management of AYA Patients With Cancer: Special Considerations}

AYA patients should be managed by a multidisciplinary team of providers with expertise in cancer treatment and management of specific developmental issues such as fertility, education, career development, employment, family planning, pregnancy, sexually transmitted diseases, and tobacco, alcohol, and substance abuse. Given the rarity of several tumor types diagnosed in this population, all AYA patients should be offered and encouraged to participate in tumor banking studies and multicenter clinical trials, when available.

All AYA patients should undergo comprehensive assessment after the diagnosis of cancer, which should include psychosocial assessment, discussion of risks of infertility associated with cancer and its treatment, the use of and education concerning fertility preservation and contraception, and genetic and familial risk assessment as appropriate based on clinical history, family history, and/or histologic diagnosis. Age- and developmentally-appropriate information related to cancer should be provided and women of childbearing potential must receive a pregnancy test before the start of therapy.

\section{Age-Appropriate Care}

AYA patients can be treated either at pediatric or at adult cancer centers. ${ }^{25}$ Retrospective analyses have shown that AYA patients with certain pediatric-type cancers, such as ALL, ${ }^{22,28-31}$ rhabdomyosarcoma, ${ }^{32}$ and Ewing sarcoma, ${ }^{33}$ have superior outcomes when treated with pediatric protocols. Alternatively, there is a lack of compelling evidence that pediatric proto- cols improve outcomes in AYA patients with AML, HL, and NHL. ${ }^{34-36}$

As mentioned earlier, the low rate of participation in clinical trials is one of the main reasons for the lack of improvement in outcomes in AYA patients with cancer. ${ }^{1,3,4,22}$ A review of 30 studies of adolescents with cancer (ages 15-19) showed that $5 \%$ to $34 \%$ of these patients enrolled in clinical trials. $^{22}$ In 20 to 25 year olds, clinical trial enrollment further decreases to approximately $2 \% .{ }^{37}$ Care should be provided at medical centers with broad access to clinical trials (standard-of-care registry trials and trials evaluating novel therapies). ${ }^{25}$ Pediatric cancer centers enroll more adolescents into clinical trials (35\% vs $12 \%$ at non-pediatric cancer centers), and AYA patients treated at pediatric cancer centers have a higher rate of clinical trial enrollment (26\%) compared with those treated at adult cancer centers (4\%)..$^{38-40}$ Parsons et $\mathrm{al}^{41}$ reported that AYA patients who are treated by non-pediatric oncologists are less likely to be enrolled in clinical trials. Nevertheless, a substantial number of AYA patients with pediatric malignancies are not being treated at pediatric cancer centers. ${ }^{22,42,43}$

The treatment and appropriate location of care vary with the type of cancer as well as with the availability of family, community, and institutional support. ${ }^{8,44}$ Most importantly, AYA patients should be evaluated at medical centers with extensive experience in treating cancer in this patient population and at centers that have access to supportive care services (psychosocial/educational support and fertility preservation) specific to the AYA population as well as to medical subspecialty services appropriate to the cancer diagnosis, such as orthopedic surgeons with experience in limb-sparing surgery for patients with extremity sarcomas. ${ }^{25}$ In a supportive care needs survey that assessed the information and service needs of young adults with cancer at a single institution, most young adults with cancer identified the following information as most important: information on their specific malignancy, effects of treatment on fertility, information on maintaining a healthy diet, and exercise/physical fitness during cancer treatment. ${ }^{45}$ Cancer centers should adopt the appropriate evidence-based approach, which includes adult centers implementing treatment based on pediatric protocols that have demonstrated superior outcomes in AYA patients and pediatric centers adopting adult 
regimens that have demonstrated benefit in this patient population.

\section{Treatment Options}

Selected AYA patients may tolerate more intensive therapies than older patients, since they have fewer comorbid conditions that limit the intensity of treatment in some older adults. ${ }^{8}$ Dose-intensive and dosedense treatment is associated with improved outcomes in some malignancies. ${ }^{19,46,47}$ Therefore, more intensive therapy may be considered for every AYA patient if such a regimen exists for that particular disease and there are no contraindications.

Treatment-related issues in AYA patients may differ from those of pediatric or older adult patients due to the distinct biology of the disease. ${ }^{13}$ Physical and physiologic changes, such as changes in body composition, size and maturity of organs, and hormones associated with the normal pubertal process, may directly affect the drug disposition, drug efficacy, and toxicity of chemotherapy in AYA patients. ${ }^{48}$ Appropriate management of symptoms and side effects to reduce the severity and toxicity of treatment should be an integral part of the management of AYA patients. ${ }^{49}$ Surgery, radiation therapy (RT), chemotherapy, and hematopoietic stem cell transplant (HSCT) are the main treatment options for patients who are able to tolerate curative treatment. All of these options are associated with both acute and late side effects. ${ }^{8,50}$

Surgery: Surgery plays an important role in the management of cancer in AYA patients, especially in breast and thyroid cancer, melanoma, bone, and soft-tissue sarcomas that are more common in AYA patients. Adolescent patients, whose bodies are still developing, may be more affected by some surgical procedures than older patients who are already at or near their full body size. ${ }^{8}$ The extent of surgery is dependent on the type and location of cancer. In some cases, extensive surgery requiring removing part or all of an organ or limb may be necessary. With advances in surgical techniques and chemotherapy, limb-sparing surgery is feasible for most patients with extremity sarcoma and osteosarcoma. ${ }^{49}$ It is imperative that surgery should be performed in high-volume centers by surgeons with expertise in the management of AYA patients, with access to rehabilitative services to ensure that function is preserved as much as possible.
RT: RT is associated with an increased risk for late mortality; development of second malignancies; pulmonary, cardiac, and thyroid dysfunction; and chronic health conditions and growth abnormalities. ${ }^{51}$ AYA patients receiving RT to testes or ovaries are at risk of developing infertility later in life. ${ }^{52}$ Women with HL who receive chest RT between 10 and 30 years of age are at increased risk of developing breast cancer. ${ }^{53}$ Cranial RT is associated with short stature, cognitive processing difficulties, and poor physical function, which contribute to lower rates of employment, independent living, and marriage among AYA cancer survivors. ${ }^{54}$ Adolescents are more vulnerable to RT-induced spinal cord dysfunction, presumably because of elongation of the cord during the growth spurt. ${ }^{55}$

Chemotherapy: Pain, fatigue, nausea, vomiting, mucositis, hair loss, infection, and myelosuppression are some of the acute side effects of chemotherapy. Reversible toxicities do not necessarily warrant dose reductions. See the NCCN Guidelines for Supportive Care (available at www.NCCN.org) for the management of treatment-related toxicities. Every attempt should be made to maintain dose intensity unless it is contraindicated. Dose reductions are often based on avoiding severe, irreversible organ damage. Significant end-organ damage may compromise long-term function and quality of life in AYA patients. Maximum cumulative dosing parameters are often established for a patient to reduce the risk of significant irreversible damage. Monitoring of cumulative dosing and dose schedule along with intensive screening is essential for patients receiving chemotherapy regimens associated with irreversible organ damage and/or infertility.

Anticipatory nausea and vomiting (ANV), also known as conditioned, learned, or psychological nausea and vomiting, is reported to occur before chemotherapy in approximately $20 \%$ of patients at any one chemotherapy cycle and in $25 \%$ to $30 \%$ of patients by their fourth chemotherapy cycle. ${ }^{56}$ Younger patients (younger than 50 years of age) may be more susceptible to ANV, because they generally receive more aggressive chemotherapy and have poorer emesis control than older patients. ${ }^{56}$ Behavioral therapy has been used in patients with $\mathrm{ANV}^{57}$ (see the NCCN Guidelines for Antiemesis).

Alkylating agent-based chemotherapy is associated with a higher risk of infertility in both male 
and female patients" (See "Impact of Cancer and Its Treatment on Fertility," page 81). Anthracycline-based chemotherapy is associated with cardiac dysfunction, whereas neurotoxic chemotherapies such as methotrexate and cytarabine can result in CNS dysfunction. ${ }^{49}$ Bleomycin-induced pulmonary toxicity is well documented in patients with $\mathrm{HL}$ treated with bleomycin-containing chemotherapy regimens. ${ }^{58}$ Higher cumulative doses of cisplatin, ifosfamide, or epipodophyllotoxins are associated with hearing loss, renal dysfunction, and secondary AML, respectively. ${ }^{59-62}$ See also the section on "Late Effects in AYA Cancer Survivors" in the complete version of these guidelines (available at NCCN.org).

HSCT: HSCT is a potentially curative treatment option for an increasing number of AYA patients with leukemias and lymphomas. ${ }^{63}$ Graft-versus-host disease (GVHD), chronic immunosuppression, and gonadal dysfunction in males and females related to high-dose conditioning chemotherapy and RT are the major post-transplant complications associated with HSCT. ${ }^{49,50}$

Chronic GVHD has been identified as the leading cause of non-relapse mortality in HSCT survivors. ${ }^{64}$ AYA patients are at a higher risk of developing chronic GVHD than younger children. ${ }^{65}$ Patient age older than 15 years (children younger than 5 years had a probability of less than $14 \%$ compared to a probability of $44 \%$ for patients older than 15 years) and the use of total body irradiation (TBI) were significantly associated with an increased likelihood of developing chronic GVHD after allogeneic HSCT. ${ }^{66}$ Patients receiving peripheral stem cells during their transplant procedure have a greater risk of chronic GVHD compared with those who received bone marrow transplant. ${ }^{67}$ A report from the Bone Marrow Transplant Registry demonstrated that chronic GVHD had a significant impact on the overall health status of HSCT survivors, particularly in the areas of functional impairment, activity limitation, and pain. ${ }^{68}$ This study also showed that resolution of chronic GVHD resulted in long-term health outcomes that were comparable to survivors who were never diagnosed with chronic GVHD.

HSCT survivors are also at increased risk for late complications, which include recurrent infections, secondary cancers, cardiac dysfunction, growth failure, weight loss, neurocognitive delay, and other end-organ dysfunction. ${ }^{49,50,69}$ In addition, the inci- dence of severe or life-threatening chronic health conditions, endocrine complications, or secondary cancers is also higher among HSCT survivors than in non-cancer populations and patients with cancer who are treated conventionally. ${ }^{63}$ Allogeneic HSCT survivors irradiated at 30 years or younger are at higher risk of developing secondary solid cancers. ${ }^{70}$

These findings highlight the increasingly recognized need for long-term follow-up care that incorporates screening and surveillance of AYA survivors of HSCT.

\section{Adherence to Treatment}

Adherence is defined as the extent to which a person's behavior corresponds with agreed recommendations from a healthcare provider. Nonadherence to recommended treatment and follow-up care contributes to poor clinical outcomes in AYA patients with cancer. ${ }^{71,72}$ Failure to keep up with appointments can lead to delayed identification of side effects, complications, or secondary cancers.

Nonadherence to treatment regimens has been an ongoing problem among patients with cancer, and the prevalence of nonadherence has been consistently higher among adolescents compared with younger or older patients with cancer. ${ }^{71}$ Nonadherence to oral chemotherapy contributes to reduced treatment efficacy and increased risk of recurrence. Available evidence from clinical trials that have included AYA patients with leukemia and lymphoma suggests that a substantial portion of AYA patients with cancer $(27 \%-63 \%)$ have difficulties adhering to their oral treatment regimens. ${ }^{71,72}$

Nonadherence to other components of cancer treatment (eg, failure to keep appointments for treatment or follow-up, refusing medical examinations, failing to prepare for procedures or therapy) was also identified in AYA patients. Treatment nonadherence in clinical trials can also interfere with adequate evaluation of the efficacy of a given treatment regimen, which in turn can invalidate the results of a clinical trial.

Risk factors for nonadherence among AYA patients include patients' emotional functioning (depression and poor/low self-esteem), personal beliefs (perceived severity of cancer diagnosis and the necessity of intervention), growing independence, competing obligations (school, work, and family), and lack of insurance and appropriate psychosocial 
support. ${ }^{73}$ In a randomized controlled trial, video game intervention significantly improved treatment adherence to prophylactic antibiotics among AYAs with acute leukemia, lymphoma, and soft tissue sarcoma. ${ }^{74}$ Additional studies evaluating the effect of interventions to improve adherence in AYA patients with cancer are needed. ${ }^{6}$

Risk assessment for nonadherence among AYA patients should include consideration of patient maturity, independence, unmet psychosocial and physical needs, and treatment side effects. ${ }^{75}$ For AYAs presumed to be at high risk of nonadherence, implementation of individualized interventions such as additional supportive care resources (eg, social work, psychology, palliative care) to promote adherence may improve outcomes. The patient's personal support system (family and friends) should be mobilized and educated to assist in relieving some of the burdens of care and to positively encourage the patient to maintain adherence to therapy. In the absence of data from studies evaluating the effect of interventions to improve adherence in AYA patients with cancer, findings from studies involving AYA patients with other chronic diseases may be able to be extrapolated to this patient population. For example, a meta-analysis showed that behavioral and multicomponent interventions have a moderate effect on improving treatment adherence in children (2-15 years of age) with chronic conditions such as diabetes, asthma, and cystic fibrosis. ${ }^{76}$

\section{NCCN Recommendations to Promote Adherence:}

- Educate about the expectations of treatment and explain the patient's responsibility to adhere to treatment. Engage in collaborative treatment decision-making with the AYA patient.

- Provide education and/or guidance about each medication before the start of treatment and every time there is a change in treatment. Review the list of medications as well as dose, purpose, and adverse effects. ${ }^{71,72}$

- Modify treatment protocol (eg, simplify dosing schedule, change timing and frequency of medication or method of administration), when medically possible, to fit into an AYA patient's lifestyle and normal activities. ${ }^{71,72}$

- Provide access to systematic and standardized symptom management for side effects related to cancer treatment. ${ }^{71,72}$ See the NCCN Guidelines for Supportive Care (available at www.NCCN. org).

\section{Impact of Cancer and Its Treatment on Fertility}

Infertility is a major consequence of cancer and its treatment in both male and female patients. ${ }^{77-80}$ The impact of cancer treatment on fertility is related to the age of the patient at the time of diagnosis and treatment and depends on the type, duration, and dose intensity of treatment. Alkylating agent-based chemotherapy, high-dose cranial RT that can impair hypothalamic pituitary function, and targeted RT to the uterus, ovaries, or testes are primary risk factors for gonadal dysfunction and decreased fertility in both females and males. ${ }^{81-87}$ Gonadal exposure to low-dose RT can result in oligospermia or azoospermia in males. Higher-dose RT is associated with both ovarian and uterine dysfunction in women.

Young women with HL treated with chemotherapy are at risk of developing premature ovarian failure, irrespective of their age at the time of treatment (38\% for those diagnosed between 30 and 40 years of age; $37 \%$ for those diagnosed between 9 and 29 years of age). The cumulative risks for premature ovarian failure are much higher after alkylating agent-based chemotherapy ${ }^{88,89}$ In a large cohort of women treated between the ages of 15 and 40 years for HL, the cumulative risk of premature ovarian failure after alkylating agent-based chemotherapy was $60 \%$ compared to only $3 \%$ or $6 \%$ after non-alkylating agentbased chemotherapy. ${ }^{89}$ Independent risk factors for acute ovarian failure include increasing RT doses to the ovaries and exposure to procarbazine and cyclophosphamide at 13 to 20 years of age. ${ }^{82}$ An analysis of 590 women who were diagnosed with HL before age 18 showed that RT to the pelvis was associated with decreased incidence of parenthood (hazard ratio [HR], 0.66; 95\% CI, 0.48-0.90; $P=.01) .90$

Among young women treated with adjuvant chemotherapy for breast cancer, the risk for premature menopause is significantly higher for women older than 35 years with newly diagnosed breast cancer treated with chemotherapy. ${ }^{91,92}$ Similarly, among female survivors of HL diagnosed between 14 and 40 years of age, women who were 22 to 39 years of age at first treatment were at a higher risk of developing premature menopause after treatment compared with younger patients (14-21 years). ${ }^{93}$ Treatment with MOPP (mechlorethamine, vincristine, procar- 
bazine, and prednisone)/ABV (doxorubicin, bleomycin, and vinblastine) significantly increased the risk of ovarian failure. After 10 years of treatment, the actuarial risk of premature menopause was $64 \%$ after high cumulative doses $\left(>8.4 \mathrm{~g} / \mathrm{m}^{2}\right)$ and $15 \%$ after low doses $\left(\leq 4.2 \mathrm{~g} / \mathrm{m}^{2}\right)$ of procarbazine. ${ }^{93}$

In male patients treated with alkylating agentbased chemotherapy and RT to testes, germ cell dysfunction with resultant infertility is more common than Leydig cell dysfunction and testosterone insufficiency. ${ }^{94}$ Leydig cell dysfunction is characterized by increased plasma concentrations of luteinizing hormone $(\mathrm{LH})$ combined with low levels of testosterone. Germ cell dysfunction is associated with reduced testicular volume, increased follicle-stimulating hormone concentrations, and reduced plasma concentrations of inhibin B. Leydig cell dysfunction occurs at RT doses higher than those associated with germ cell dysfunction. AYA men treated with testicular RT $\geq 20$ Gy are at high risk for Leydig cell dysfunction, whereas testicular RT $\geq 2$ Gy can impair spermatogenesis resulting in permanent azoospermia. ${ }^{94}$ TBI used as part of high-dose conditioning therapy before HSCT can also affect the testes, resulting in permanent infertility in most AYA men. ${ }^{52}$

Azoospermia is associated with chemotherapy and radiation. Whether it is transient or permanent depends on the type of treatment involved, with radiation and alkylating agents posing the greatest risk for long-term damage. ${ }^{95}$ Azoospermia has been reported in more than $90 \%$ of men receiving procarbazine-based chemotherapy regimens such as MOPP and may not resolve over time, resulting in permanent infertility. ${ }^{96}$ Alternatively, the ABVD (doxorubicin, bleomycin, vinblastine, and dacarbazine) regimen has been shown to be less gonadotoxic, with a vast majority of patients regaining normal fertility after completion of treatment. ${ }^{97}$ Cisplatin-based chemotherapy for testicular cancer is associated with temporary azoospermia in most men, with a recovery of spermatogenesis in about $50 \%$ to $80 \%$ of patients after 2 to 5 years. ${ }^{97} \mathrm{RT}>2$ Gy to the testes, moderateto high-dose alkylating agent chemotherapy (MOPP $>3$ cycles), higher cumulative alkylating agent dose (busulfan $>600 \mathrm{mg} / \mathrm{m}^{2}$, cyclophosphamide $>7.5 \mathrm{~g} / \mathrm{m}^{2}$, or ifosfamide $>60 \mathrm{mg} / \mathrm{m}^{2}$ ), or any alkylating agent combined with RT to testes or TBI are considered risk factors for oligospermia and azoospermia. ${ }^{77,85}$ Pelvic RT and cumulative cyclophosphamide doses
$>9.5 \mathrm{~g} / \mathrm{m}^{2}$ are associated with a high risk of permanent infertility as seen in male patients with NHL, Ewing sarcoma, and soft tissue sarcomas. ${ }^{98,99}$ Retroperitoneal lymph node dissection is also associated with infertility in men with testicular cancer. ${ }^{100}$

The NCCN Guidelines recommend discussing the risks of infertility due to cancer and its treatment with all patients at the time of diagnosis, before starting treatment. This is especially important for patients who will be starting therapies with a high risk of affecting fertility, as described previously.

\section{Fertility Preservation}

Fertility preservation is an issue of crucial importance in AYA patients and should be an essential part in the management of their cancer. ${ }^{16,52,101-105}$ The ASCO Clinical Practice Guidelines recommend that providers discuss the options for fertility preservation with all new patients with cancer at diagnosis. ${ }^{106}$ Nevertheless, fertility preservation is currently one of the most underprescribed and least implemented services in AYA patients with cancer. ${ }^{52,101,107}$ A study that reviewed 231 records of AYA patients with leukemia/lymphoma, sarcoma, or breast or testicular cancers showed that infertility risk was discussed $26 \%$ of the time and fertility preservation options were discussed $24 \%$ of the time. ${ }^{108}$ However, it is possible that more discussions about infertility occurred without having been documented. Another study that analyzed the electronic medical records of 454 AYA patients at a single cancer center showed that the risk of infertility was discussed with $83 \%$ of patients, with women more likely to be informed than men (odds ratio [OR], 3.57; 95\% CI, 1.33-9.60; $\mathrm{P}=.01) .{ }^{109}$ A study of 146 adolescent boys at risk for infertility due to cancer treatment across 8 different pediatric oncology centers found that only $53.4 \%$ attempted to bank sperm, with $43.8 \%$ successfully banking. Parent or medical team recommendation was associated with increased likelihood of sperm banking completion. ${ }^{110}$

Psychosocial providers can assist patients and families in the decision-making process about fertility preservation, particularly when AYA patients are distressed about the potential infertility associated with cancer treatment. ${ }^{106}$ The Oncofertility Consortium, a group of clinicians and researchers in the United States, was formed in 2007 to address reproductive barriers facing AYA patients and to identify 
research priorities in this area. ${ }^{111}$ Future aims developed during a 2011 meeting are as follows:

- Determine optimal techniques for cryopreservation of reproductive tissue and gametes;

- Further investigate in vitro follicle maturation in primates;

- Investigate AYA patients' psychosocial needs as part of the fertility preservation plan;

- Improve patient-provider communication regarding fertility preservation; and

- Develop and perform multicenter studies, using the preexisting infrastructure of the National Physicians Cooperative.

Options for Females: Ideally, fertility preservation should be initiated before the start of treatment. However, in some situations, when it is impractical or impossible to pursue fertility preservation before starting therapy, it may be appropriate to readdress later in the course of treatment.

Oophoropexy and embryo cryopreservation after in vitro fertilization (IVF) are two established options for fertility preservation in females. ${ }^{106}$ Oophoropexy involves surgically displacing the ovaries out of the RT field to minimize ovarian damage and has been shown to preserve ovarian function. ${ }^{112}$ Embryo cryopreservation after IVF has been highly successful in women younger than 40 years of age. ${ }^{52,101}$ However, this method requires a male partner or sperm donor who is available with short notice. In one study that assessed pregnancy outcomes following embryo cryopreservation, letrozole was used in combination with follicle-stimulating hormone to protect patients with breast cancer against the harmful effects of increased estrogen. ${ }^{113}$ Of 33 women, the live birth rate was $45 \%$, with $39 \%$ of live births resulting in twins. These rates are not significantly different from those for infertile couples not affected by cancer, except for implantation rate, which was greater in the patients with breast cancer $(40.7 \%$ vs $26.1 \%)$. A little over half $(55 \%)$ of the embryos were transferred to a gestational carrier, with no significant differences in outcomes (ie, implantation, live birth, twinning rates) between self-transfers and gestational carriers.

Mature oocyte cryopreservation is an alternative for single women, but, like embryo cryopreservation, requires hormone stimulation. ${ }^{52,101}$ Evidence from randomized trials ${ }^{114-117}$ and a meta-analysis ${ }^{118}$ suggest that IVF with cryopreserved oocytes results in fertilization and pregnancy rates similar to that of fresh oocytes. Oocyte cryopreservation is no longer considered investigational according to guidelines from the American Society of Reproductive Medicine. ${ }^{119}$

Ovarian tissue cryopreservation is a promising, but less well studied strategy for female fertility preservation when there is insufficient time for oocyte or embryo cryopreservation and/or the patient is prepubertal. This technique does not require hormonal stimulation, so there is no long delay in initiation of treatment. ${ }^{52}$ Although evidence supporting the effectiveness and safety of ovarian tissue cryopreservation is scare, a few systematic reviews have supported its use for fertility preservation in cancer patients. ${ }^{120,121}$ This procedure would not be appropriate for some women with cancer, where there is a potential for reintroduction of malignant cells that could occur with grafting. Although ovarian tissue cryopreservation is still considered investigational at some institutions, it may be discussed as an option for fertility preservation, if available. Xenotransplantation of ovarian tissue is currently under investigation. ${ }^{122}$

Some studies, including randomized trials, have evaluated the role of menstrual suppression with gonadotropin-releasing hormone $(\mathrm{GnRH}$; also known as LH-releasing hormone [LHRH]) agonists to preserve ovarian function during chemotherapy. ${ }^{123-131}$ Some meta-analyses have shown that GnRH agonist may be beneficial for fertility preservation. ${ }^{132-134}$ However, the impact of these meta-analyses are limited by flaws such as only examining women with breast cancer and only including trials that were not adequately powered and did not use blinding and/ or a placebo condition. ${ }^{135,136}$ Further, results from earlier meta-analyses were inconsistent, with some showing a potential benefit of $\mathrm{GnRH}$ to preservation of ovarian function, ${ }^{137-139}$ while other reviews have been unable to come to this conclusion. ${ }^{140,141}$ Also, limited data are available on the long-term impact of $\mathrm{GnRH}$ on preservation of ovarian function, ${ }^{132}$ though a 5-year follow-up analysis of a randomized trial showed that administration of a GnRH agonist does not significantly impact premature ovarian failure or future pregnancy rate. ${ }^{131}$ Therefore, though data suggest that menstrual suppression with GnRH agonists may protect ovarian function, further investigation is needed.

Other agents, such as the progestin medroxyprogesterone and oral contraceptives, may be used in women with hematologic malignancies who are at 
risk for menorrhagia, but this does not preserve ovarian function. ${ }^{142}$ However, caution is needed in endometrial cancer, where progestin therapy has been associated with high rates of cancer recurrence. ${ }^{143}$ This may be prevented by combining metformin with medroxyprogesterone. ${ }^{144}$

Options for Males: Semen cryopreservation before the start of treatment is the most reliable and wellestablished means of preserving fertility in AYA males with cancer. ${ }^{52,101}$ The success of sperm banking may be limited in some patients, such as those with HL and testicular cancer, who may already have azoospermia associated with the disease. Depending on the type of chemotherapy, semen collection may be possible after start of chemotherapy; however, the impact of chemotherapy and RT on the risk of genetic defects in the offspring remains unknown. ${ }^{145}$

Cryopreservation and subsequent transplantation of spermatogonial stem cells is experimental but may be an alternative option for some patients in whom semen cryopreservation is not possible. ${ }^{52,101}$ There is limited evidence regarding the efficacy of hormone suppression in reducing the risk of male infertility during chemotherapy. ${ }^{106}$

Recommendations for Fertility Preservation: The NCCN Guidelines emphasize that fertility preservation, as well as sexual health and function, should be an essential component of the management of AYA patients, who may be at risk for infertility due to cancer treatments. Options for fertility preservation should be discussed with all patients before the start of treatment and providers should initiate referral to fertility preservation clinics within 24 hours for all patients who choose the option of fertility preservation. Local or institutional grants may be available to provide financial assistance with fertility preservation needs. Follow-up with a fertility specialist after treatment may also be helpful for some patients. Referral to a mental health professional to assist with complex decision-making is recommended.

Females:

- Oophoropexy should be considered for all female patients who will be receiving RT.

- Embryo or oocyte cryopreservation should be discussed, if it is possible to delay treatment long enough for a cycle of oocyte stimulation, espe- cially for patients with low- and intermediaterisk HL, low-grade sarcomas, and breast cancer. ${ }^{119}$

- Ovarian tissue cryopreservation may be considered, if available. ${ }^{120}$

- Medroxyprogesterone, oral contraceptives, or GnRH agonists can be used in protocols that are predicted to cause prolonged thrombocytopenia and thus present a risk for menorrhagia. ${ }^{142}$

- Some data suggest that menstrual suppression with GnRH agonists may protect ovarian function. ${ }^{128,132,134}$ However, evidence that menstrual suppression with GnRH agonists protects ovarian function is insufficient, so this procedure is not currently recommended as an option for fertility preservation.

Males:

- Discuss the possibility of sperm banking at diagnosis. AYA patients can use either a local sperm bank or an available online sperm banking kit.

- Oncology centers that treat AYA patients should develop a system for offering sperm banking to all AYA patients in a systematic and patientcentered manner.

\section{Contraception During and After Treatment for Cancer}

Male condoms may be safely used by AYA males with cancer. ${ }^{146}$ AYA women with cancer have unique contraception needs, and the options are dependent on the type of cancer, its treatment, and treatmentrelated complications. ${ }^{147}$ The NCCN Guidelines recommend discussion about the use of contraception before starting therapy. ${ }^{147}$

Long-acting reversible contraception (LARC) with intrauterine devices (IUDs) or implantable contraceptives are more effective than short-term contraceptive methods, which include the use of estrogen and progestin with various delivery systems. ${ }^{148}$ LARC has been shown to be superior to short-acting contraceptives in AYA women. ${ }^{149,150}$ In a study of 4,167 women (14-45 years of age), LARC was associated with higher 12 -month adherence rates than oral contraceptive pills ( $86 \%$ vs. $55 \%) .{ }^{149}$ In a large, prospective study involving 7,487 women, the contraceptive failure rate was significantly higher for those using oral contraceptive pills, patch, or ring compared to those using LARC (4.55 vs 0.27 ), and the failure rates among women younger than 21 
years were twice as great as in women 21 years of age or older. ${ }^{150}$

The Society of Family Planning guidelines recommend the use of IUDs or implantable contraceptives for most women who are receiving treatment for cancer. ${ }^{151}$ The use of any method of contraception is recommended for women who have been free of cancer for at least 6 months and have no history of hormonally mediated cancers, chest RT, anemia, osteoporosis, or venous thromboembolism (VTE). ${ }^{151}$ The use of IUDs is considered the preferred firstline contraceptive option for women with a history of breast cancer, although for women treated with tamoxifen, a levonorgestrel-containing intrauterine system (IUS) may be preferable since it has been shown to reduce tamoxifen-induced endometrial changes without increasing the risk of breast cancer recurrence. Levonorgestrel-containing IUS may also be used to minimize menstrual blood loss in women with iron-deficiency anemia. ${ }^{151}$

Due to the risk of VTE associated with the use of combined hormonal contraceptive methods, the U.S. Centers for Disease Control and Prevention recommend that the use of these contraceptive methods should be avoided in women of childbearing age with active cancer or who have been treated for cancer in the past 6 months. ${ }^{152,153}$

\section{Management of Cancer During Pregnancy}

All women of childbearing potential must receive a pregnancy test before starting therapy. Cancer is diagnosed in about $0.1 \%$ of pregnant women and is the second most common cause of maternal death during pregnancy. ${ }^{154}$ Cervical, breast, thyroid, and ovarian cancers, melanoma, lymphoma, and leukemia are the most common cancers diagnosed during pregnancy. ${ }^{155-158}$ These are also the most common cancers diagnosed in the AYA population. ${ }^{159}$ An analysis of 1963 to 2007 data from the Swedish Multi-Generation Register and the National Cancer Register showed a lower-than-expected number of cancers diagnosed during pregnancy, and a rebound in the number of cases of melanoma, CNS cancers, breast cancer, and thyroid cancer in postpartum women. ${ }^{158}$ This rebound may be due to changes in the mammary and thyroid glands being overlooked during the postpartum period. Despite some persisting beliefs, there is no evidence of pregnancy-associated relapse in female survivors of HL. ${ }^{160}$
Although research on the prognosis of cancer during pregnancy is limited, a few meta-analyses and systematic reviews have suggested that the prognosis of certain cancers (eg, breast, melanoma, vulvar) may be worse when occurring concurrent with pregnancy compared to the same cancers occurring outside pregnancy. ${ }^{161-164}$ These results may be confounded by factors related to the patients' pregnancy, delays in diagnosis, and differences in treatment decisions, making a definitive conclusion difficult.

Accurate diagnosis of the type and stage of cancer using appropriate imaging studies (ultrasound, chest $\mathrm{x}$-ray, and mammogram) with abdominal shielding and limiting fetal exposure to ionizing radiation is an essential step in the management of cancer during pregnancy. ${ }^{165-167}$ There is insufficient evidence regarding the safety of gadolinium-based contrast agents in pregnant women. ${ }^{167}$ Surgery is possible at any time during pregnancy depending on the anatomic location of the tumor, although it may be beneficial to delay surgery, when possible, until after fetus viability. ${ }^{165,167}$ Selection of an appropriate treatment plan for pregnant women is dependent on individual tumor biology and tumor stage, similar to the management of cancer in non-pregnant women. In addition to the disease characteristics in pregnant women, the gestational age of the fetus is a significant factor in the selection of treatment. ${ }^{165}$

RT is contraindicated during pregnancy. However, in very rare instances when RT is necessary, it should be delivered in low therapeutic doses (with adequate uterine shielding to minimize fetal exposure) with the goals of controlling maternal cancer and providing the fetus the best chance for survival with normal development. ${ }^{168}$ The dose to the fetus can be reduced by using modified RT administration techniques or adding additional shielding between the treatment machine and the patient. ${ }^{168}$ Early collaboration among the radiation oncologist, medical physicist, medical and/or surgical oncologist, and obstetrician is essential. The American College of Radiology has developed guidelines with an objective to assist practitioners in identifying pregnancy, preventing unnecessary irradiation of pregnant AYA women, tailoring examinations to effectively manage RT dose, and developing strategies to quantify and evaluate the potential effects of RT delivered to patients who are pregnant. ${ }^{169}$ In 2014, an international consensus panel composed of researchers and 
clinicians who are experts in treatment of cancer during pregnancy also developed guidelines for RT in women who are pregnant. ${ }^{166}$

Chemotherapy should be avoided during the first trimester because of greater risk of teratogenic effects, which include major congenital malformations, impaired organ function, spontaneous abortions, and fetal death. ${ }^{167,170-173}$ Although the use of chemotherapy during the second and third trimesters has not been associated with significant teratogenic effects, it may be associated with low birth weight, preterm labor, and intrauterine growth restriction. ${ }^{157,170,172,174-176}$ However, a multicenter, prospective case-control study of children born to mothers with cancer (129 cases, 129 controls) showed no significant impact of chemotherapy treatment on cognitive, cardiac, and general development of the offspring. ${ }^{177}$ Potential benefits and risks of chemotherapy for both the mother and fetus must be carefully evaluated before the start of treatment. Delayed treatment until after fetal maturity, with careful follow-up to rule out disease progression, is a safe option for women diagnosed with early-stage cancers. ${ }^{178,179}$ In some women diagnosed with advanced-stage disease with an urgent need to start chemotherapy in the first trimester, potential benefits and risks of chemotherapy for both the mother and fetus must be carefully evaluated before initiation of treatment. ${ }^{157}$ Due to the severe teratogenic effects of methotrexate, it should not be used for the treatment of cancer in women at any stage of pregnancy. ${ }^{172}$ Older-generation alkylating agents (eg, procarbazine, busulfan), thalidomide, lenalidomide, pomalidomide, and tretinoin are also considered teratogenic and are contraindicated during pregnancy. ${ }^{166}$ The safety and efficacy of hormonal agents and targeted therapies have not yet been evaluated in well-controlled studies including pregnant women. ${ }^{165-167,180-182}$ Currently, the use of such agents in pregnant women is not recommended.

Supportive care for the management of treatment-related side effects should be integrated into treatment planning based on the trimester of pregnancy. Granulocyte-colony stimulating factors for the management of neutropenia and antiemetics for the management of nausea and vomiting have been used in pregnant women without any significant side effects. ${ }^{166,181,183,184}$

The panel members acknowledged that the management of cancer during pregnancy poses signifi- cant diagnostic and therapeutic challenges for both the patient and the physician. The guidelines recommend that AYA women diagnosed with cancer during pregnancy require individualized treatment from a multidisciplinary team involving medical, surgical, and radiation oncologists, gynecologic oncologists, obstetricians, and perinatologists as appropriate. . $^{157,166}$ Referral to tertiary cancer centers with expertise in the diagnosis of cancer during pregnancy and maternal-fetal medicine and knowledge of the physiologic changes that occur during pregnancy should be strongly encouraged.

\section{Psychosocial and Behavioral Issues}

AYA patients diagnosed with and treated for cancer have psychosocial issues that are distinct from those of pediatric and adult patients. ${ }^{6,9-12}$ AYA patients 20 to 29 years of age are significantly less likely to use professional mental health services than teens and older patients 30 to 39 years of age. AYA patients in the 20- to 29-year age group are also significantly more likely to report an unmet need with regard to receiving age-appropriate information about their cancer. Some of the challenges faced by AYA patients and survivors include maintaining an active and independent life, coping with treatment-related side effects and stress, seeking and understanding information, accepting cancer, and maintaining a positive attitude. ${ }^{185}$ AYA men and women go through developmental stages marked by rapid changes in cognitive and emotional growth, and these issues need to be considered while delivering developmentally appropriate psychosocial and supportive care to AYA patients. ${ }^{186}$

Few measurement tools have been developed to better understand health-related quality of life in AYA patients with cancer. ${ }^{6}$ Palmer et al ${ }^{187}$ developed an AYA Oncology Psychosocial Screening Tool to assist clinicians in supporting psychosocial coping during active treatment and promoting healthy post-treatment survivorship in AYA patients. This screening tool has 4 main areas: a distress thermometer, a check list of "areas of concern," a tick box for information provision, and signatures. Further validation of this tool and its use will help clinicians to improve psychosocial care for AYA patients, regardless of where they receive treatment. ${ }^{187}$ 
Psychosocial needs for AYA patients should be assessed across the following domains: 1) individual function (psychosocial, emotional, and behavioral issues); 2) relationships (family, peers, and health care professionals); and, 3) socioeconomic issues. Age and developmentally appropriate supportive care services and interventions should be used to address each of these domains.

\section{Individual Function}

Psychosocial Issues: AYA patients must cope with cancer treatment while accomplishing key developmental tasks such as identity development, including sexual identity; peer involvement; initiating intimate and emotional relationships; establishing autonomy from parents; maintaining personal values; fostering self-esteem and resilience; and independently making decisions about their future that involve education, career, or employment. ${ }^{188-191}$ The impact of diagnosis and treatment of cancer on their physical appearance, sexual development, and sexual function can lead to shame, social isolation, and regressive behaviors if not addressed promptly. Cancer and its often intensive and lengthy treatments put AYA patients at risk for disruptions in their normal activities. Interruptions of school or work due to treatment will have negative consequences for their long-term career opportunities, financial status, and lifetime earnings. ${ }^{185}$ During the treatment period, AYA patients should have the opportunity to live as normal a life as possible, continue their education and/or careers, and participate in the many milestones of their lives. ${ }^{192}$ Physical and/or occupational therapy may help AYA patients transition back to a lifestyle appropriate for their age group. ${ }^{193}$

Emotional Issues: Cancer-related issues such as confrontation with mortality and loss of fertility can result in significant emotional distress and psychiatric symptoms such as depression and anxiety in AYA patients. These feelings are related to patients' cognitive capacity to understand the severity of their disease while sometimes lacking fully mature cognitive and emotional coping abilities. ${ }^{185}$ Psychological distress is significantly greater among AYAs compared with older adults. ${ }^{194-198}$

In a longitudinal study that assessed the prevalence of psychological distress in 215 AYA patients with cancer (15-39 years of age) during the first year after diagnosis, distress symptoms exceeded population norms at the time of diagnosis and at 12-month follow-up. ${ }^{195}$ In this study, $12 \%$ of AYA patients reported clinically significant chronic distress throughout the first 12 months after diagnosis and an additional 15\% reported delayed distress.

In addition to distress, depression and anxiety are commonly experienced by AYA cancer survivors. An analysis from the Childhood Cancer Survivor Study (CCSS) showed that survivors of AYA cancer $(n=$ 2,589) report higher rates of depression (OR, 1.55; 95\% CI, 1.04-2.30) and anxiety (OR, 2.00; 95\% CI, 1.17-3.43), compared with their siblings $(n=391){ }^{199}$ Another study of 5,341 cancer survivors diagnosed at age 25 or earlier found that survivors were more likely to be prescribed antidepressants compared to age- and gender-matched controls (26.9/1,000 person-years for survivors vs $22.5 / 1,000$ person-years in controls; HR $=1.19 ; 95 \% \mathrm{CI}, 1.12-1.28) .{ }^{200}$

The need for information, counseling, and practical support was reported in 57\%, 41\%, and 39\% of AYA patients, respectively, at 12 months after the diagnosis of cancer. ${ }^{197}$ Kazak et $\mathrm{al}^{201}$ reported that intensive cancer treatments during adolescence are associated with inferior psychosocial outcomes and health beliefs in survivors compared with their age-matched peers. Psychological problems are also associated with an increased risk for obesity and poor health behavior, which may increase future risk for chronic health conditions and secondary neoplasms. ${ }^{202}$

Behavioral Issues: AYA patients with cancer may engage in risky behaviors (tobacco, alcohol, cannabis, or substance use/abuse) that may impair their health. Older age at cancer diagnosis, lower household income, less education, no pulmonary-related cancer treatment, and no brain RT were independently associated with a statistically significant relative risk of smoking initiation. ${ }^{203}$ The risk factors associated with heavy drinking included fair or poor self-assessed health, depression, anxiety, somatization, activity limitations, and cancer-related fears and uncertainty. ${ }^{204}$ Low perception of susceptibility to late effects, older adolescence compared with early adolescence, and worry were the strongest predictors of substance abuse. ${ }^{205}$ Although AYA patients may be aware of the complications associated with tobacco, alcohol, cannabis, or substance use/abuse during their treatment, they may not avoid them 
throughout their treatment because these habits make them feel normal and like part of their peer group. Clinicians working with this population need to be aware of this and address the issues in a sensitive and confidential manner. ${ }^{192,206}$

Studies have shown increased rates of mental illness and cognitive impairment among adolescent cannabis users compared with adults with similar usage habits. ${ }^{207}$ Heavy or regular use of cannabis in adolescents has been associated with impairments in attention, learning, memory, planning, and psychomotor speed. An earlier age of onset of cannabis use exacerbates these adverse effects. If an AYA patient chooses to continue use of cannabis, education on methods for lowering risk of adverse effects is recommended. For example, the patient may be counseled to avoid high tetrahydrocannabinol (THC)-content products, avoid synthetic cannabinoids, chose routes of administration other than inhalation of combusted cannabis, limit frequency of use, and never drive while impaired. ${ }^{208}$

AYA patients are also vulnerable to sexual and reproductive health complications that should be addressed before, during, and after completion of treatment. ${ }^{147}$ Traditional risk-taking behaviors of AYA individuals coupled with a compromised immune system can put AYA patients with cancer and survivors at a greater risk of sexually transmitted infections. See the section on "Contraception During and After Treatment for Cancer" (page 84) for more discussion of appropriate contraception choices for patients with cancer and survivors.

AYA patients have nutritional concerns that are different from those of children and adults, especially among younger patients in this population. Adolescents are dependent on their families for food preparation and may experience peer pressure when eating at school or with friends. Diet/nutrition information has been reported as an unmet need among AYA patients. ${ }^{10}$ Nutritional requirements and potential deficits should be evaluated based on the patient's age.

\section{NCCN Recommendations For Supportive Care Services/Interventions for Psychosocial and Behavioral Issues:}

- Provide information about reliable online sources to access developmentally appropriate information related to their cancer. See "Online Resources for AYA Patients and Survivors" in the complete version of these guidelines, at NCCN. org.

- For all AYA patients, provide counseling around decision-making regarding the risks of infertility associated with cancer and its treatment and the use of fertility preservation and contraception before starting treatment. ${ }^{209}$

- Because the incidence of sexually transmitted infections peaks among AYAs 15 to 24 years of age, provide preventive health education about sexually transmitted diseases. ${ }^{192}$

- Prescribe and provide nutrition and exercise recommendations for all AYA patients. Refer to a registered dietitian-certified specialist in oncology. ${ }^{210}$

- Consider flexible treatment dates, consultation times, and procedures when possible to enable AYA patients to continue with their treatment without interrupting their school/work or other normal activities. ${ }^{192}$

- Offer psychosocial support and counseling to help alleviate distress. See the NCCN Guidelines for Distress Management (available at NCCN.org).

- Refer AYA patients with cognitive dysfunction or other psychiatric symptoms (eg, depression or anxiety) to a mental health provider and community-based resources serving AYA patients.

- Refer patients with signs, symptoms, and a history of substance abuse or addiction to a risk reduction or substance abuse management program. Refer to smoking cessation program if needed (see NCCN Guidelines for Smoking Cessation (available at NCCN.org).

- Refer patients experiencing challenges with their faith or belief in a just or fair world to faithbased resources or activities (eg, church youth groups, mentors). ${ }^{11,211}$

- For those who desire to receive complementary and alternative medicine, refer them to reputable providers of these services.

\section{Relationships}

Social, Peer, and Family Relationships: AYA patients often have to endure lengthy hospital stays under the supervision of healthcare providers, resulting in significant isolation from their family members and peer group. ${ }^{192}$ Isolation and alienation are common among AYA individuals diagnosed with cancer, 
because they often miss out on the life experiences shared by their non-ill peers. Reinforcing relationships with family, peers, and health professionals is an important aspect of life for AYA patients. ${ }^{186,212}$

Although some studies have identified family support and cohesiveness as important contributors to a survivor's adjustment, others have identified the important role played by same-aged peers (healthy peers as well as other AYA cancer survivors) in helping AYA patients cope with cancer and overcome feelings of loneliness. ${ }^{11,186}$ In one study, AYA patients with cancer (16-22 years of age) identified social support (including family members, friends, healthcare providers, and other patients) as their major coping strategy. ${ }^{213}$ In another study, some AYA patients and survivors reported that opportunities to meet other young adult survivors were more important than the support they received from family and peers. ${ }^{209}$

Peer support programs assist AYA patients and survivors in establishing and maintaining relationships with their healthy peers as well as with other AYA patients with cancer, offer opportunities to achieve age-related developmental tasks (building interpersonal and problem-solving skills), and promote positive psychosocial growth. ${ }^{209,214}$ Peer support also provides AYA patients with an opportunity to address areas of shared concern, such as uncertainty about the future, establishing autonomy while being increasingly dependent on family and friends, sexual identity, and infertility, thereby reducing feelings of social isolation. ${ }^{214}$

AYA peer support groups have been developed in a variety of formats, including face-to-face meetings, camp style formats, or online support groups. ${ }^{215,216}$ Social networking groups focused on supporting AYA patients are particularly helpful for exchanging 2 primary types of support-informational and emotional-through providing advice and empathizing with other AYA patients dealing with cancer. ${ }^{216}$ Summer camps and adventure programs where participants are physically challenged have resulted in improvements in self-confidence, independence, and social contacts. ${ }^{11,215}$ Many of the AYA patients may not be interested in conventional cancer support groups but are willing to participate in social networking events involving other AYA patients, survivors, and family members. ${ }^{11}$ Indeed, studies of AYA patients and survivors indicated that $73 \%$ of patients currently receiving therapy and $74 \%$ of off-treatment survivors reported that their needs for retreats and camp programs were unmet. ${ }^{217,218}$

\section{Communications with Healthcare Professionals:}

Communicating information to AYA patients can be challenging, especially because several subgroups within the AYA population have different levels of cognitive and emotional development. Establishing direct communication with the patients on an individual basis, with sufficient sensitivity to each patient's needs and preferences is very important. ${ }^{25}$ Although some patients prefer not to receive direct communication about their cancer, others may desire to take a more prominent role in the management of their care. For the latter group, information should be provided directly to patients in a developmentally appropriate manner, allowing time to process the information and deliver information in a caring manner. ${ }^{219}$ AYA patients prefer that information about their cancer and cancer-related risks be communicated to them in a manner that is positive, respectful, and nonjudgmental. ${ }^{192}$ In a pilot project aimed at eliciting the views of AYA patients with cancer, humor, closely followed by expertise and knowledge, was identified as the most important characteristic that patients would like to see in their nurses. ${ }^{220}$ Since there is evidence that AYA patients are willing to use the internet to get health information and support, it will also be helpful to provide them with a list of recommended and reliable age-appropriate online sources to access information about their cancer, particularly with regard to treatment and late effects, fertility preservation, mental health counseling, peer support groups, diet, and nutrition. ${ }^{215,218,221}$ See "Online Resources for AYA Patients and Survivors" in the complete version of these guidelines, at NCCN.org.

\section{NCCN Recommendations for Supportive Care Services/Interventions for AYA Patient Relationships:}

- Promote communication between AYA patients and family members (parents, spouse/partners, and siblings). ${ }^{26}$

- Provide information to family members and partners about psychosocial support and behavioral services to increase awareness of the possible psychosocial issues associated with diagnosis of cancer in AYAs.

- Consider family-based intervention models from pediatrics (eg, parent support groups, Impact of Traumatic Stressors Interview Schedule). ${ }^{17}$ 
- Establish direct communication with individual patients, providing developmentally appropriate information about their cancer, treatment options, and potential side effects, thus reinforcing the importance of AYA involvement in decision-making. ${ }^{25,209}$

- Some AYA patients prefer not to share information about their cancer with their family in an effort to shield their family members from some of the things they themselves worry about. Therefore, obtain their permission to share information with other family members and encourage completion of a HIPAA release form.

- Provide information about peer support and social networking opportunities and create flexible visiting hours and an environment that will encourage peers to visit AYA patients. ${ }^{192}$

- Encourage completion of a medical power of attorney when appropriate.

\section{Socioeconomic Issues}

AYA patients are much more likely to be uninsured or underinsured individuals than adults or children, with many in transition between their parents' insurance and their independent insurance. ${ }^{17}$ Young adult survivors of childhood cancers are more likely to report health-related unemployment, lower rates of health insurance coverage, and more difficulties obtaining coverage compared with their siblings. ${ }^{222} \mathrm{An}$ analysis of 9,353 AYA patients with HL showed that having either public or no health insurance was associated with poorer HL-specific survival compared with patients with private or military insurance (HR, 2.08; 95\% CI, 1.52-2.84). ${ }^{223}$ Furthermore, unemployment and lack of health insurance appear to be significant predictors of psychological distress in the childhood cancer survivor population. ${ }^{224}$ Uninsured AYA patients are also less likely to participate in clinical trials. ${ }^{41}$ As described previously, advanced stage of cancer at diagnosis and lack of health insurance were significantly associated with longer time to cancer diagnosis in AYAs. ${ }^{225}$ Greater rates of unemployment and lack of health insurance among AYA patients and survivors are also associated with limited access to long-term follow-up care. ${ }^{185}$ Results from the AYA HOPE study, a population-based cohort study of 523 AYA patients with cancer (15-39 years of age at diagnosis from 2007-2009), suggest that lack of health insurance is also associated with poor health-related quality of life among AYA patients with cancer. ${ }^{226}$

AYA patients with employment also experience problems in obtaining affordable health and life insurance due to their pre-existing cancer history. ${ }^{11}$ Even those with relatively comprehensive insurance may be liable for substantial out-of-pocket expenses related to treatment, such as transportation costs associated with traveling for treatment, accommodations, meals, and childcare as well as expenses not related to treatment. ${ }^{11}$ AYA patients who are financially independent also have to face an additional burden of loss of income because of their inability to work during treatment. Once the treatment is over, AYA patients with cancer also need long-term follow-up care for monitoring and treatment of late effects.

\section{NCCN Recommendations For Supportive Care} Services/Interventions for Socioeconomic Issues:

- Assess AYA patients' health insurance status and provide information on potential sources of coverage (eg, Medicaid, Health Insurance Marketplace, parent's insurance,) and other key elements associated with insurance coverage.

- Educate AYA patients about the benefits for which they may qualify (eg, short- or long-term disability, state disability benefits, Social Security benefits, and public assistance benefits).

- Provide a referral for transportation assistance programs (eg, van ride programs, voucher programs) for AYA patients who must travel to receive treatment. Identify resources for respite care that would be helpful for those with young children.

- Integrate financial assistance for AYA cancer survivors into their survivorship plans.

\section{Palliative and End-of-life Care}

Palliative care is interdisciplinary care of patients with life-threatening illnesses, malignant as well as non-malignant. The goal of palliative care in patients with cancer is to control symptoms, relieve emotional and physical suffering from adverse effects of treatment, and improve quality of life for patients and their families, regardless of the stage of the disease or the need for other therapies. ${ }^{227,228}$ See the NCCN Guidelines for Palliative Care (available at NCCN.org). 
Palliative care services for AYA patients should be provided by a multidisciplinary team with expertise in understanding the psychosocial, emotional, developmental, and financial issues that are unique to this age group. ${ }^{227,229}$ Introduction of palliative care for symptom management and psychosocial support should occur before the patient's condition is considered "palliative" in order to provide the best possible care. ${ }^{230}$ Palliative care is appropriate even when patients are being treated with curative intent, and there is growing consensus that AYA patients should have access to palliative care services from the time of diagnosis until the time of death or cure. ${ }^{230}$ Patients, caregivers, and healthcare professionals should be taught that palliative care is an integral part of their comprehensive cancer care. ${ }^{229}$ AYA patients usually do not make decisions in isolation. Although some AYA patients have the ability to make life and death decisions independently, many are either not the primary decision maker or they rely intensely on input from parents, spouses, significant others, and other family members. ${ }^{227}$ Palliative care services should also consider the psychosocial needs of the patient's family, friends, and caregivers. ${ }^{230} \mathrm{~Pa}$ tients' goals, dreams, and desires to leave a legacy are important considerations to address. ${ }^{229}$

End-of-life care involves the palliation of symptoms, management of delirium, existential distress, discussion about the place of death, and support of family. ${ }^{227,229}$ It is imperative for healthcare professionals not to assume that AYA patients may be less inclined to discuss death and other end-of-life issues. ${ }^{227}$ In an exploratory study of 50 adolescent patients (15-21 years of age) with and without chronic illnesses, adolescents were willing to discuss end-oflife decision-making by taking part in a one-on-one survey administered by a researcher. ${ }^{231}$ The quality of life of AYA patients should be heeded by the care team. ${ }^{229}$ During palliative and end-of-life care, AYA patients may be able to and wish to continue to en- gage in day-to-day activities, even if some activities are in discord with medical advice (eg, participating in strenuous physical activity).

Discussion about end-of-life preferences should begin at the time of starting treatment, but details should be individualized according to the preferences of the AYA patient and family. ${ }^{232}$ A chart review regarding end-of-life care in 663 AYA patients showed that these patients receive medically intensive therapy at about the same rates as older patients, indicating a need for better understanding of care preferences in these patients. ${ }^{233}$ AYA patients' opinions about end-of-life care vary across this age group. Exploring individual preferences for end-of-life care and providing interventions specific to the needs of this patient population could significantly improve end-of-life care. ${ }^{232,234}$ In one retrospective review, a significant number of adolescents dying of cancer felt that discussions about end-of-life occurred very close to death, allowing very little time to psychologically prepare for death. ${ }^{235}$ Physicians with expertise in end-of-life care should facilitate discussion of difficult issues such as nutrition/hydration, sedation, treatment cessation, and place of death. ${ }^{227}$ An advance care planning document is recommended for terminally ill AYA patients with metastatic cancer. $^{232,236}$ Ongoing psychosocial support is extremely important during the transition to end-of-life care.

\section{Summary}

AYA patients with cancer should be recognized as a distinct population that has unique medical and psychosocial needs. It is important for physicians to identify issues specific to the AYA population and recommend appropriate interventions with the aim of improving clinical outcomes. Most importantly, all AYA patients should have access to age-appropriate supportive care as well as medical subspecialty services appropriate for their cancer diagnosis.

\section{References}

1. Bleyer A, O'Leary M, Barr R, Ries LA, eds. Cancer Epidemiology in Older Adolescents and Young Adults 15 to 29 Years of Age, Including SEER Incidence and Survival: 1975-2000. National Cancer Institute, NIH Pub. No. 06-5767. Bethesda, MD 2006. Available at: http://www.seer.cancer. gov/publications/aya/. Accessed December 15, 2017.

2. Keegan TH, Ries LA, Barr RD, et al. Comparison of cancer survival trends in the United States of adolescents and young adults with those in children and older adults. Cancer 2016;122:1009-1016.

3. Burke ME, Albritton K, Marina N. Challenges in the recruitment of adolescents and young adults to cancer clinical trials. Cancer 2007;110:2385-2393.

4. Ferrari A, Montello M, Budd T, Bleyer A. The challenges of clinical trials for adolescents and young adults with cancer. Pediatr Blood Cancer 2008;50:1101-1104.

5. Tai E, Beaupin L, Bleyer A. Clinical trial enrollment among adolescents with cancer: supplement overview. Pediatrics 2014;133 Suppl 3:S85-90.

6. Smith AW, Seibel NL, Lewis DR, et al. Next steps for adolescent and young adult oncology workshop: an update on progress and recommendations for the future. Cancer 2016;122:988-999. 
7. Bleyer A, Budd T, Montello M. Adolescents and young adults with cancer: the scope of the problem and criticality of clinical trials. Cancer 2006;107:1645-1655.

8. Bleyer A. Young adult oncology: the patients and their survival challenges. CA Cancer J Clin 2007;57:242-255.

9. Abrams AN, Hazen EP, Penson RT. Psychosocial issues in adolescents with cancer. Cancer Treat Rev 2007;33:622-630.

10. Zebrack BJ, Block R, Hayes-Lattin B, et al. Psychosocial service use and unmet need among recently diagnosed adolescent and young adult cancer patients. Cancer 2013;119:201-214.

11. Zebrack BJ. Psychological, social, and behavioral issues for young adults with cancer. Cancer 2011;117:2289-2294.

12. Zebrack B, Butler M. Context for understanding psychosocial outcomes and behavior among adolescents and young adults with cancer. J Natl Compr Canc Netw 2012;10:1151-1156.

13. Bleyer A, Barr R, Hayes-Lattin B, et al. The distinctive biology of cancer in adolescents and young adults. Nat Rev Cancer 2008;8:288-298.

14. Tricoli JV, Blair DG, Anders CK, et al. Biologic and clinical characteristics of adolescent and young adult cancers: acute lymphoblastic leukemia, colorectal cancer, breast cancer, melanoma, and sarcoma. Cancer 2016;122:1017-1028.

15. Ramphal R, Meyer R, Schacter B, et al. Active therapy and models of care for adolescents and young adults with cancer. Cancer 2011;117:2316-2322.

16. Nass SJ, Beaupin LK, Demark-Wahnefried W, et al. Identifying and addressing the needs of adolescents and young adults with cancer: summary of an Institute of Medicine workshop. Oncologist 2015;20:186-195.

17. Closing the Gap: Research and Care Imperatives for Adolescents and Young Adults With Cancer: Report of the Adolescent and Young Adult Oncology Progress Review Group. Available at: https://www.cancer.gov/ types/aya/research/ayao-august-2006.pdf. Accessed December 15, 2017.

18. Trama A, Botta L, Foschi R, et al. Survival of European adolescents and young adults diagnosed with cancer in 2000-07: population-based data from EUROCARE-5. Lancet Oncol 2016;17:896-906.

19. Womer RB, West DC, Krailo MD, et al. Randomized controlled trial of interval-compressed chemotherapy for the treatment of localized Ewing sarcoma: a report from the Children's Oncology Group. J Clin Oncol 2012;30:4148-4154.

20. Lee J, Hoang BH, Ziogas A, Zell JA. Analysis of prognostic factors in Ewing sarcoma using a population-based cancer registry. Cancer 2010;116:19641973.

21. Verma V, Denniston KA, Lin CJ, Lin C. A comparison of pediatric vs. adult patients with the Ewing sarcoma family of tumors. Front Oncol 2017;7:82.

22. Tai E, Buchanan N, Westervelt L, et al. Treatment setting, clinical trial enrollment, and subsequent outcomes among adolescents with cancer: a literature review. Pediatrics 2014;133 Suppl 3:S91-97.

23. Bleyer A, Viny A, Barr R. Cancer in 15- to 29-year-olds by primary site. Oncologist 2006;11:590-601.

24. Ward E, DeSantis C, Robbins A, et al. Childhood and adolescent cancer statistics, 2014. CA Cancer J Clin 2014;64:83-103.

25. Ferrari A, Thomas D, Franklin AR, et al. Starting an adolescent and young adult program: some success stories and some obstacles to overcome. J Clin Oncol 2010;28:4850-4857.

26. Zebrack B, Mathews-Bradshaw B, Siegel S. Quality cancer care for adolescents and young adults: a position statement. J Clin Oncol 2010;28:4862-4867.

27. Alvarez E, Keegan T, Johnston EE, et al. Adolescent and young adult oncology patients: disparities in access to specialized cancer centers. Cancer 2017;123:2516-2523

28. Boissel N, Auclerc M-F, Lheritier V, et al. Should adolescents with acute lymphoblastic leukemia be treated as old children or young adults? Comparison of the French FRALLE-93 and LALA-94 trials. J Clin Oncol 2003;21:774-780.

29. Ribera J-M, Oriol A, Sanz M-A, et al. Comparison of the results of the treatment of adolescents and young adults with standard-risk acute lymphoblastic leukemia with the Programa Espanol de Tratamiento en Hematologia pediatric-based protocol ALL-96. J Clin Oncol 2008;26:1843-1849.

30. Stock W, La M, Sanford B, et al. What determines the outcomes for adolescents and young adults with acute lymphoblastic leukemia treated on cooperative group protocols? A comparison of Children's Cancer Group and Cancer and Leukemia Group B studies. Blood 2008;112:1646-1654.

31. Huguet F, Leguay T, Raffoux E, et al. Pediatric-inspired therapy in adults with Philadelphia chromosome-negative acute lymphoblastic leukemia: the GRAALL-2003 study. J Clin Oncol 2009;27:911-918.
32. Ferrari A, Dileo P, Casanova M, et al. Rhabdomyosarcoma in adults. A retrospective analysis of 171 patients treated at a single institution. Cancer 2003;98:571-580.

33. Scurr M, Judson I. How to treat the Ewing's family of sarcomas in adult patients. Oncologist 2006;11:65-72.

34. Tai E, Pollack LA, Townsend J, et al. Differences in non-Hodgkin lymphoma survival between young adults and children. Arch Pediat Adolesc Med 2010;164:218-224.

35. Sandlund JT. Should adolescents with NHL be treated as old children or young adults? Hematology Am Soc Hematol Educ Program 2007:297-303.

36. Burkhardt B, Oschlies I, Klapper W, et al. Non-Hodgkin's lymphoma in adolescents: experiences in 378 adolescent NHL patients treated according to pediatric NHL-BFM protocols. Leukemia 2011;25:153-160.

37. Bleyer WA. Cancer in older adolescents and young adults: epidemiology, diagnosis, treatment, survival, and importance of clinical trials. Med Pediatr Oncol 2002;38:1-10.

38. Bleyer WA, Tejeda H, Murphy SB, et al. National cancer clinical trials: children have equal access; adolescents do not. J Adolesc Health 1997;21:366-373.

39. Shochat SJ, Fremgen AM, Murphy SB, et al. Childhood cancer: patterns of protocol participation in a national survey. CA Cancer J Clin 2001;51:119-130.

40. Downs-Canner S, Shaw PH. A comparison of clinical trial enrollment between adolescent and young adult (AYA) oncology patients treated at affiliated adult and pediatric oncology centers. J Pediatr Hematol Oncol 2009;31:927-929.

41. Parsons HM, Harlan LC, Seibel NL, et al. Clinical trial participation and time to treatment among adolescents and young adults with cancer: does age at diagnosis or insurance make a difference? J Clin Oncol 2011;29:4045-4053.

42. Howell DL, Ward KC, Austin HD, et al. Access to pediatric cancer care by age, race, and diagnosis, and outcomes of cancer treatment in pediatric and adolescent patients in the state of Georgia. J Clin Oncol 2007;25:4610 4615 .

43. Albritton $\mathrm{KH}$, Wiggins $\mathrm{CH}$, Nelson HE, Weeks JC. Site of oncologic specialty care for older adolescents in Utah. J Clin Oncol 2007;25:46164621 .

44. Bleyer A. The Quid Pro Quo of pediatric versus adult services for older adolescent cancer patients. Pediatr Blood Cancer 2010;54:238-241.

45. Gupta AA, Edelstein K, Albert-Green A, D'Agostino N. Assessing information and service needs of young adults with cancer at a single institution: the importance of information on cancer diagnosis, fertility preservation, diet, and exercise. Support Care Cancer 2013;21:2477-2484.

46. DeAngelo DJ, Stevenson KE, Dahlberg SE, et al. Long-term outcome of a pediatric-inspired regimen used for adults aged $18-50$ years with newly diagnosed acute lymphoblastic leukemia. Leukemia 2015;29:526-534.

47. Gerber NK, Wexler LH, Singer S, et al. Adult rhabdomyosarcoma survival improved with treatment on multimodality protocols. Int J Radiat Oncol Biol Phys 2013;86:58-63.

48. Veal GJ, Hartford CM, Stewart CF. Clinical pharmacology in the adolescent oncology patient. J Clin Oncol 2010;28:4790-4799.

49. Oeffinger KC, Mertens AC, Hudson MM, et al. Health care of young adult survivors of childhood cancer: a report from the Childhood Cancer Survivor Study. Ann Fam Med 2004;2:61-70.

50. Oeffinger KC, Hudson MM. Long-term complications following childhood and adolescent cancer: foundations for providing risk-based health care for survivors. CA Cancer J Clin 2004;54:208-236.

51. Armstrong GT, Stovall M, Robison LL. Long-term effects of radiation exposure among adult survivors of childhood cancer: results from the childhood cancer survivor study. Radiat Res 2010;174:840-850.

52. Levine J, Canada A, Stern CJ. Fertility preservation in adolescents and young adults with cancer. J Clin Oncol 2010;28:4831-4841.

53. Travis LB, Hill DA, Dores GM, et al. Breast cancer following radiotherapy and chemotherapy among young women with Hodgkin disease. JAMA 2003;290:465-475.

54. Janson C, Leisenring W, Cox C, et al. Predictors of marriage and divorce in adult survivors of childhood cancers: a report from the Childhood Cancer Survivor Study. Cancer Epidemiol Biomarkers Prev 2009;18:2626-2635.

55. Bleyer A, Choi M, Wang SJ, et al. Increased vulnerability of the spinal cord to radiation or intrathecal chemotherapy during adolescence: a report from the Children's Oncology Group. Pediatr Blood Cancer 2009;53:12051210 .

56. Roscoe JA, Morrow GR, Aapro MS, et al. Anticipatory nausea and vomiting. Support Care Cancer 2011;19:1533-1538. 
57. Figueroa-Moseley C, Jean-Pierre P, Roscoe JA, et al. Behavioral interventions in treating anticipatory nausea and vomiting. J Natl Compr Canc Netw 2007;5:44-50.

58. Huang TT, Hudson MM, Stokes DC, et al. Pulmonary outcomes in survivors of childhood cancer: a systematic review. Chest 2011;140:881901.

59. Schell MJ, McHaney VA, Green AA, et al. Hearing loss in children and young adults receiving cisplatin with or without prior cranial irradiation. J Clin Oncol 1989;7:754-760.

60. Skinner R, Cotterill SJ, Stevens MC. Risk factors for nephrotoxicity after ifosfamide treatment in children: a UKCCSG Late Effects Group study. United Kingdom Children's Cancer Study Group. Br J Cancer 2000;82:1636-1645.

61. Knight KR, Kraemer DF, Neuwelt EA. Ototoxicity in children receiving platinum chemotherapy: underestimating a commonly occurring toxicity that may influence academic and social development. J Clin Onco 2005;23:8588-8596.

62. Hijiya N, Ness KK, Ribeiro RC, Hudson MM. Acute leukemia as a secondary malignancy in children and adolescents: current findings and issues. Cancer 2009;115:23-35.

63. Armenian SH, Sun CL, Kawashima T, et al. Long-term health-related outcomes in survivors of childhood cancer treated with hematopoietic cell transplantation (HCT) versus conventional therapy: a report from the Bone Marrow Transplant Survivor Study (BMTSS) and Childhood Cancer Survivor Study (CCSS). Blood 2011;118:1413-1420.

64. Wingard JR, Majhail NS, Brazauskas R, et al. Long-term survival and late deaths after allogeneic hematopoietic cell transplantation. J Clin Oncol 2011;29:2230-2239.

65. Flowers ME, Inamoto Y, Carpenter PA, et al. Comparative analysis of risk factors for acute graft-versus-host disease and for chronic graft-versus-host disease according to National Institutes of Health consensus criteria. Blood 2011;117:3214-3219.

66. Zecca M, Prete A, Rondelli R, et al. Chronic graft-versus-host disease in children: incidence, risk factors, and impact on outcome. Blood 2002;100:1192-1200

67. Anasetti C, Logan BR, Lee SJ, et al. Peripheral-blood stem cells versus bone marrow from unrelated donors. N Engl J Med 2012;367:1487-1496.

68. Fraser CJ, Bhatia S, Ness K, et al. Impact of chronic graft-versus-host disease on the health status of hematopoietic cell transplantation survivors: a report from the Bone Marrow Transplant Survivor Study. Blood 2006;108:2867-2873.

69. Inaba $\mathrm{H}$, Yang J, Kaste SC, et al. Longitudinal changes in body mass and composition in survivors of childhood hematologic malignancies after allogeneic hematopoietic stem-cell transplantation. J Clin Oncol 2012;30:3991-3997.

70. Rizzo JD, Curtis RE, Socie G, et al. Solid cancers after allogeneic hematopoietic cell transplantation. Blood 2009;113:1175-1183.

71. Butow $P$, Palmer S, Pai A, et al. Review of adherence-related issues in adolescents and young adults with cancer. J Clin Oncol 2010;28:4800_ 4809 .

72. Kondryn HJ, Edmondson CL, Hill J, Eden TO. Treatment nonadherence in teenage and young adult patients with cancer. Lancet Oncol 2011;12:100-108

73. Windebank KP, Spinetta JJ. Do as I say or die: compliance in adolescents with cancer. Pediatr Blood Cancer 2008;50:1099-1100.

74. Kato PM, Cole SW, Bradlyn AS, Pollock BH. A video game improves behavioral outcomes in adolescents and young adults with cancer: a randomized trial. Pediatrics 2008;122:e305-317.

75. Rosenberg AR, Macpherson CF, Kroon L, Johnson R. Rethinking adherence: a proposal for a new approach to risk assessment. J Adolesc Young Adult Oncol 2013;2:83-86.

76. Kahana S, Drotar D, Frazier T. Meta-analysis of psychological interventions to promote adherence to treatment in pediatric chronic health conditions. J Pediatr Psychol 2008;33:590-611.

77. Kenney LB, Cohen LE, Shnorhavorian M, et al. Male reproductive health after childhood, adolescent, and young adult cancers: a report from the Children's Oncology Group. J Clin Oncol 2012;30:3408-3416.

78. Metzger ML, Meacham LR, Patterson B, et al. Female reproductive health after childhood, adolescent, and young adult cancers: guidelines for the assessment and management of female reproductive complications. J Clin Oncol 2013;31:1239-1247.

79. Gunnes MW, Lie RT, Bjorge T, et al. Reproduction and marriage among male survivors of cancer in childhood, adolescence and young adulthood: a national cohort study. Br J Cancer 2016;114:348-356.
80. Chow EJ, Stratton KL, Leisenring WM, et al. Pregnancy after chemotherapy in male and female survivors of childhood cancer treated between 1970 and 1999: a report from the Childhood Cancer Survivor Study cohort. Lancet Oncol 2016;17:567-576.

81. Wallace WH, Anderson RA, Irvine DS. Fertility preservation for young patients with cancer: who is at risk and what can be offered? Lancet Oncol 2005;6:209-218.

82. Chemaitilly W, Mertens AC, Mitby P, et al. Acute ovarian failure in the childhood cancer survivor study. J Clin Endocrinol Metab 2006;91:1723_ 1728 .

83. Darzy KH. Radiation-induced hypopituitarism after cancer therapy: who, how and when to test. Nat Clin Pract Endocrinol Metab 2009;5:88-99.

84. Green DM, Sklar CA, Boice JD, Jr., et al. Ovarian failure and reproductive outcomes after childhood cancer treatment: results from the Childhood Cancer Survivor Study. J Clin Oncol 2009;27:2374-2381

85. Green DM, Kawashima T, Stovall M, et al. Fertility of male survivors of childhood cancer: a report from the Childhood Cancer Survivor Study. J Clin Oncol 2010;28:332-339.

86. Barton SE, Najita JS, Ginsburg ES, et al. Infertility, infertility treatment, and achievement of pregnancy in female survivors of childhood cancer: a report from the Childhood Cancer Survivor Study cohort. Lancet Oncol 2013;14:873-881.

87. van Dorp W, Mulder RL, Kremer LC, et al. Recommendations for premature ovarian insufficiency surveillance for female survivors of childhood, adolescent, and young adult cancer: a report from the International Late Effects of Childhood Cancer Guideline Harmonization Group in collaboration with the PanCareSurFup Consortium. J Clin Oncol 2016;34:3440-3450.

88. Haukvik UKH, Dieset I, Bjoro T, et al. Treatment-related premature ovarian failure as a long-term complication after Hodgkin's lymphoma. Ann Oncol 2006;17:1428-1433.

89. van der Kaaij MA, Heutte N, Meijnders P, et al. Premature ovarian failure and fertility in long-term survivors of Hodgkin's lymphoma: a European Organisation for Research and Treatment of Cancer Lymphoma Group and Groupe d'Etude des Lymphomes de l'Adulte Cohort Study. J Clin Oncol 2012;30:291-299.

90. Bramswig JH, Riepenhausen M, Schellong G. Parenthood in adult female survivors treated for Hodgkin's lymphoma during childhood and adolescence: a prospective, longitudinal study. Lancet Oncol 2015;16:667675.

91. Bines J, Oleske DM, Cobleigh MA. Ovarian function in premenopausal women treated with adjuvant chemotherapy for breast cancer. J Clin Oncol 1996;14:1718-1729

92. Goodwin PJ, Ennis M, Pritchard KI, et al. Risk of menopause during the first year after breast cancer diagnosis. J Clin Oncol 1999;17:2365-2370.

93. De Bruin ML, Huisbrink J, Hauptmann M, et al. Treatment-related risk factors for premature menopause following Hodgkin lymphoma. Blood 2008;111:101-108.

94. Chemaitilly W, Sklar CA. Endocrine complications in long-term survivors of childhood cancers. Endocr Relat Cancer 2010;17:R141-159.

95. Meistrich ML. Effects of chemotherapy and radiotherapy on spermatogenesis in humans. Fertil Steril 2013;100:1180-1186.

96. Sieniawski M, Reineke T, Josting A, et al. Assessment of male fertility in patients with Hodgkin's lymphoma treated in the German Hodgkin Study Group (GHSG) clinical trials. Ann Oncol 2008;19:1795-1801.

97. Howell SJ, Shalet SM. Spermatogenesis after cancer treatment: damage and recovery. J Natl Cancer Inst Monogr 2005:12-17.

98. Meistrich ML, Wilson G, Brown BW, et al. Impact of cyclophosphamide on long-term reduction in sperm count in men treated with combination chemotherapy for Ewing and soft tissue sarcomas. Cancer 1992;70:27032712 .

99. Pryzant RM, Meistrich ML, Wilson G, et al. Long-term reduction in sperm count after chemotherapy with and without radiation therapy for nonHodgkin's lymphomas. J Clin Oncol 1993;11:239-247.

100. Matos E, Skrbinc B, Zakotnik B. Fertility in patients treated for testicular cancer. J Cancer Surviv 2010;4:274-278.

101. Wallace WH. Oncofertility and preservation of reproductive capacity in children and young adults. Cancer 2011;117:2301-2310.

102. Redig AJ, Brannigan R, Stryker SJ, et al. Incorporating fertility preservation into the care of young oncology patients. Cancer 2011;117:4-10.

103. Fernbach A, Lockart B, Armus CL, et al. Evidence-based recommendations for fertility preservation options for inclusion in treatment protocols for pediatric and adolescent patients diagnosed with cancer. J Pediatr Oncol Nurs 2014;31:211-222. 
104. Benedict C, Thom B, N Friedman D, et al. Young adult female cancer survivors' unmet information needs and reproductive concerns contribute to decisional conflict regarding posttreatment fertility preservation. Cancer 2016;122:2101-2109.

105. Waks AG, Partridge AH. Fertility preservation in patients with breast cancer: necessity, methods, and safety. J Natl Compr Canc Netw 2016;14:355-363.

106. Loren AW, Mangu PB, Beck LN, et al. Fertility preservation for patients with cancer: American Society of Clinical Oncology clinical practice guideline update. J Clin Oncol 2013;31:2500-2510.

107. Johnson RH, Kroon L. Optimizing fertility preservation practices for adolescent and young adult cancer patients. J Natl Compr Canc Netw 2013;11:71-77.

108. Quinn GP, Block RG, Clayman ML, et al. If you did not document it, it did not happen: rates of documentation of discussion of infertility risk in adolescent and young adult oncology patients' medical records. J Oncol Pract 2015;11:137-144.

109. Salsman JM, Yanez B, Smith $\mathrm{KN}$, et al. Documentation of fertility preservation discussions for young adults with cancer: examining compliance with treatment guidelines. J Natl Compr Canc Netw 2016;14:301-309.

110. Klosky JL, Wang F, Russell KM, et al. Prevalence and predictors of sperm banking in adolescents newly diagnosed with cancer: examination of adolescent, parent, and provider factors influencing fertility preservation outcomes. J Clin Oncol 2017; 35:3830-3836.

111. Waimey KE, Duncan FE, Su HI, et al. Future directions in oncofertility and fertility preservation: a report from the 2011 Oncofertility Consortium Conference. J Adolesc Young Adult Oncol 2013;2:25-30.

112. Terenziani M, Piva L, Meazza C, et al. Oophoropexy: a relevant role in preservation of ovarian function after pelvic irradiation. Fertil Steril 2009;91:935 e15-16.

113. Oktay K, Turan V, Bedoschi G, et al. Fertility preservation success subsequent to concurrent aromatase inhibitor treatment and ovarian stimulation in women with breast cancer. J Clin Oncol 2015;33:24242429.

114. Cobo A, Kuwayama M, Perez S, et al. Comparison of concomitant outcome achieved with fresh and cryopreserved donor oocytes vitrified by the Cryotop method. Fertil Steril 2008;89:1657-1664.

115. Cobo A, Meseguer M, Remohi J, Pellicer A. Use of cryo-banked oocytes in an ovum donation programme: a prospective, randomized, controlled, clinical trial. Hum Reprod 2010;25:2239-2246.

116. Rienzi L, Romano S, Albricci L, et al. Embryo development of fresh 'versus' vitrified metaphase II oocytes after ICSI: a prospective randomized siblingoocyte study. Hum Reprod 2010;25:66-73.

117. Parmegiani L, Cognigni GE, Bernardi S, et al. Efficiency of aseptic open vitrification and hermetical cryostorage of human oocytes. Reprod Biomed Online 2011;23:505-512.

118. Cobo A, Diaz C. Clinical application of oocyte vitrification: a systematic review and meta-analysis of randomized controlled trials. Fertil Steril 2011;96:277-285.

119. Mature oocyte cryopreservation: a guideline. Fertility and sterility 2013;99:37-43.

120. Salama M, Woodruff TK. New advances in ovarian autotransplantation to restore fertility in cancer patients. Cancer Metastasis Rev 2015;34:807822.

121. Ladanyi C, Mor A, Christianson MS, et al. Recent advances in the field of ovarian tissue cryopreservation and opportunities for research. J Assist Reprod Genet 2017;34:709-722.

122. Dittrich R, Lotz L, Fehm T, et al. Xenotransplantation of cryopreserved human ovarian tissue--a systematic review of MII oocyte maturation and discussion of it as a realistic option for restoring fertility after cancer treatment. Fertil Steril 2015;103:1557-1565.

123. Del Mastro L, Boni L, Michelotti A, et al. Effect of the gonadotropinreleasing hormone analogue triptorelin on the occurrence of chemotherapyinduced early menopause in premenopausal women with breast cancer: a randomized trial. JAMA 2011;306:269-276.

124. Behringer $\mathrm{K}$, Wildt $\mathrm{L}$, Mueller $\mathrm{H}$, et al. No protection of the ovarian follicle pool with the use of GnRH-analogues or oral contraceptives in young women treated with escalated BEACOPP for advanced-stage Hodgkin lymphoma. Final results of a phase II trial from the German Hodgkin Study Group. Ann Oncol 2010;21:2052-2060.

125. Gerber B, von Minckwitz G, Stehle H, et al. Effect of luteinizing hormonereleasing hormone agonist on ovarian function after modern adjuvant breast cancer chemotherapy: the GBG 37 ZORO study. J Clin Oncol 2011;29:2334-2341.

126. Demeestere I, Brice P, Peccatori FA, et al. Gonadotropin-releasing hormone agonist for the prevention of chemotherapy-induced ovarian failure in patients with lymphoma: 1-year follow-up of a prospective randomized trial. J Clin Oncol 2013;31:903-909.

127. Elgindy EA, El-Haieg DO, Khorshid OM, et al. Gonadatrophin suppression to prevent chemotherapy-induced ovarian damage: a randomized controlled trial. Obstet Gynecol 2013;121:78-86.

128. Moore HC, Unger JM, Phillips KA, et al. Goserelin for ovarian protection during breast-cancer adjuvant chemotherapy. N Engl J Med 2015;372:923932.

129. Bildik G, Akin N, Senbabaoglu F, et al. GnRH agonist leuprolide acetate does not confer any protection against ovarian damage induced by chemotherapy and radiation in vitro. Hum Reprod 2015;30:2912-2925.

130. Blumenfeld Z, Zur H, Dann EJ. Gonadotropin-releasing hormone agonist cotreatment during chemotherapy may increase pregnancy rate in survivors. Oncologist 2015;20:1283-1289.

131. Demeestere I, Brice P, Peccatori FA, et al. No evidence for the benefit of gonadotropin-releasing hormone agonist in preserving ovarian function and fertility in lymphoma survivors treated with chemotherapy: final longterm report of a prospective randomized trial. J Clin Oncol 2016;34:25682574.

132. Del Mastro L, Ceppi M, Poggio F, et al. Gonadotropin-releasing hormone analogues for the prevention of chemotherapy-induced premature ovarian failure in cancer women: systematic review and meta-analysis of randomized trials. Cancer Treat Rev 2014;40:675-683.

133. Lambertini $M$, Ceppi $M$, Poggio $F$, et al. Ovarian suppression using luteinizing hormone-releasing hormone agonists during chemotherapy to preserve ovarian function and fertility of breast cancer patients: a metaanalysis of randomized studies. Ann Oncol 2015;26:2408-2419.

134. Munhoz RR, Pereira AA, Sasse AD, et al. Gonadotropin-releasing hormone agonists for ovarian function preservation in premenopausal women undergoing chemotherapy for early-stage breast cancer: a systematic review and meta-analysis. JAMA Oncol 2016;2:65-73.

135. Rodriguez-Wallberg K, Turan V, Munster P, Oktay K. Can ovarian suppression with gonadotropin-releasing hormone analogs (GnRHa) preserve fertility in cancer patients? Ann Oncol 2016;27:257.

136. Oktay K, Turan V. Failure of ovarian suppression with gonadotropinreleasing hormone analogs to preserve fertility: an assessment based on the quality of evidence. JAMA Oncol 2016;2:74-75.

137. Bedaiwy MA, Abou-Setta AM, Desai N, et al. Gonadotropin-releasing hormone analog cotreatment for preservation of ovarian function during gonadotoxic chemotherapy: a systematic review and meta-analysis. Fertil Steril 2011;95:906-914 e901-904.

138. Wang C, Chen M, Fu F, Huang M. Gonadotropin-releasing hormone analog cotreatment for the preservation of ovarian function during gonadotoxic chemotherapy for breast cancer: a meta-analysis. PLoS One 2013;8:e66360.

139. Yang B, Shi W, Yang J, et al. Concurrent treatment with gonadotropinreleasing hormone agonists for chemotherapy-induced ovarian damage in premenopausal women with breast cancer: a meta-analysis of randomized controlled trials. Breast 2013;22:150-157.

140. Ben-Aharon I, Gafter-Gvili A, Leibovici L, Stemmer SM. Pharmacological interventions for fertility preservation during chemotherapy: a systematic review and meta-analysis. Breast Cancer Res Treat 2010;122:803-811.

141. Kim SS, Lee JR, Jee BC, et al. Use of hormonal protection for chemotherapyinduced gonadotoxicity. Clin Obstet Gynecol 2010;53:740-752.

142. Bates JS, Buie LW, Woodis CB. Management of menorrhagia associated with chemotherapy-induced thrombocytopenia in women with hematologic malignancy. Pharmacotherapy 2011;31:1092-1110.

143. Park JY, Nam JH. Progestins in the fertility-sparing treatment and retreatment of patients with primary and recurrent endometrial cancer. Oncologist 2015;20:270-278.

144. Mitsuhashi A, Sato $\mathrm{Y}$, Kiyokawa $\mathrm{T}$, et al. Phase II study of medroxyprogesterone acetate plus metformin as a fertility-sparing treatment for atypical endometrial hyperplasia and endometrial cancer. Ann Oncol 2016;27:262-266.

145. Williams DH. Sperm banking and the cancer patient. Ther Adv Urol 2010;2:19-34.

146. Laurence V, Gbolade BA, Morgan SJ, Glaser A. Contraception for teenagers and young adults with cancer. Eur J Cancer 2004;40:2705-2716. 
147. Murphy D, Klosky JL, Termuhlen A, et al. The need for reproductive and sexual health discussions with adolescent and young adult cancer patients. Contraception 2013;88:215-220.

148. Committee on Adolescent Health Care Long-Acting Reversible Contraception Working Group. The American College of Obstetricians and Gynecologists. Committee opinion no. 539: adolescents and longacting reversible contraception: implants and intrauterine devices. Obstet Gynecol 2012;120:983-988.

149. Peipert JF, Zhao Q, Allsworth JE, et al. Continuation and satisfaction of reversible contraception. Obstet Gynecol 2011;117:1105-1113.

150. Winner B, Peipert JF, Zhao Q, et al. Effectiveness of long-acting reversible contraception. N Engl J Med 2012;366:1998-2007.

151. Patel A, Schwarz EB, Society of Family Planning. Cancer and contraception. Release date May 2012. SFP Guideline \#20121. Contraception 2012;86:191-198.

152. Curtis KM, Tepper NK, Jatlaoui TC, et al. U.S. Medical Eligibility Criteria for Contraceptive Use, 2016. MMWR Recomm Rep 2016;65(No. RR3):1-103.

153. Centers for Disease Control and Prevention. U.S. Medical Eligibility Criteria for Contraceptive Use, 2010. MMWR Early Release 2010;59(No. RR-4):1-85.

154. Pavlidis NA. Coexistence of pregnancy and malignancy. Oncologist 2002;7:279-287.

155. Azim HA Jr, Pavlidis N, Peccatori FA. Treatment of the pregnant mother with cancer: a systematic review on the use of cytotoxic, endocrine, targeted agents and immunotherapy during pregnancy. Part II: Hematological tumors. Cancer Treat Rev 2010;36:110-121.

156. Azim HA Jr, Peccatori FA, Pavlidis N. Treatment of the pregnant mothe with cancer: a systematic review on the use of cytotoxic, endocrine, targeted agents and immunotherapy during pregnancy. Part I: solid tumors. Cancer Treat Rev 2010;36:101-109.

157. Van Calsteren K, Heyns L, De Smet F, et al. Cancer during pregnancy: an analysis of 215 patients emphasizing the obstetrical and the neonatal outcomes. J Clin Oncol 2010;28:683-689.

158. Andersson TM, Johansson AL, Fredriksson I, Lambe M. Cancer during pregnancy and the postpartum period: a population-based study. Cancer 2015;121:2072-2077.

159. Howlader N, Noone A, Krapcho M, et al, eds. SEER Cancer Statistics Review, 1975-2014, National Cancer Institute. Bethesda, MD. Available at: https://seer.cancer.gov/csr/1975_2014/, based on November 2016 SEER data submission, posted to the SEER web site, April 2017. Accessed December 11, 2017

160. Weibull CE, Eloranta S, Smedby KE, et al. Pregnancy and the risk of relapse in patients diagnosed with Hodgkin lymphoma. J Clin Oncol 2016;34:337-344

161. Kyrgidis A, Lallas A, Moscarella E, et al. Does pregnancy influence melanoma prognosis? A meta-analysis. Melanoma Res 2017;27:289-299.

162. Hartman EK, Eslick GD. The prognosis of women diagnosed with breast cancer before, during and after pregnancy: a meta-analysis. Breast Cancer Res Treat 2016;160:347-360.

163. Azim HA Jr, Santoro L, Russell-Edu W, et al. Prognosis of pregnancyassociated breast cancer: a meta-analysis of 30 studies. Cancer Treat Rev 2012;38:834-842.

164. Matsuo K, Whitman SA, Blake EA, et al. Feto-maternal outcome of pregnancy complicated by vulvar cancer: a systematic review of literature. Eur J Obstet Gynecol Reprod Biol 2014;179:216-223.

165. Pentheroudakis G, Orecchia R, Hoekstra HJ, Pavlidis N. Cancer, fertility and pregnancy: ESMO Clinical Practice Guidelines for diagnosis, treatment and follow-up. Ann Oncol 2010;21(Suppl 5):v266-273.

166. Lishner M, Avivi I, Apperley JF, et al. Hematologic malignancies in pregnancy: management guidelines from an international consensus meeting. J Clin Oncol 2016;34:501-508.

167. Loibl S, Schmidt A, Gentilini O, et al. Breast Cancer Diagnosed During Pregnancy: Adapting Recent Advances in Breast Cancer Care for Pregnant Patients. JAMA Oncol 2015;1:1145-1153.

168. Martin DD. Review of radiation therapy in the pregnant cancer patient Clin Obstet Gynecol 2011;54:591-601.

169. ACR-SPR practice guideline for imaging pregnant or potentially pregnant adolescents and women with ionizing radiation. Available at: https://www. acr.org/-/media/ACR/Files/Practice-Parameters/pregnant-pts.pdf.

170. Cardonick E, Iacobucci A. Use of chemotherapy during human pregnancy. Lancet Oncol 2004;5:283-291

171. Brewer M, Kueck A, Runowicz CD. Chemotherapy in pregnancy. Clin Obstet Gynecol 2011;54:602-618.
172. Koren G, Carey N, Gagnon R, et al. Cancer chemotherapy and pregnancy. J Obstet Gynaecol Can 2013;35:263-280.

173. Pinnix CC, Osborne EM, Chihara D, et al. Maternal and fetal outcomes after therapy for Hodgkin or non-Hodgkin lymphoma diagnosed during pregnancy. JAMA Oncol 2016;2:1065-1069.

174. Cardonick E, Usmani A, Ghaffar S. Perinatal outcomes of a pregnancy complicated by cancer, including neonatal follow-up after in utero exposure to chemotherapy: results of an international registry. Am J Clin Oncol 2010;33:221-228.

175. Amant F, Han SN, Gziri MM, et al. Chemotherapy during pregnancy. Curr Opin Oncol 2012;24:580-586.

176. Loibl S, Han SN, von Minckwitz G, et al. Treatment of breast cancer during pregnancy: an observational study. Lancet Oncol 2012;13:887-896.

177. Amant F, Vandenbroucke $T$, Verheecke $M$, et al. Pediatric outcome after maternal cancer diagnosed during pregnancy. $\mathrm{N}$ Engl J Med 2015;373:1824-1834.

178. Duggan B, Muderspach LI, Roman LD, et al. Cervical cancer in pregnancy: reporting on planned delay in therapy. Obstet Gynecol 1993;82:598-602.

179. Cold S, During M, Ewertz M, et al. Does timing of adjuvant chemotherapy influence the prognosis after early breast cancer? Results of the Danish Breast Cancer Cooperative Group (DBCG). Br J Cancer 2005;93:627-632.

180. Amant F, Loibl S, Neven $P$, Van Calsteren $K$. Breast cancer in pregnancy. Lancet 2012;379:570-579.

181. Brenner B, Avivi I, Lishner M. Haematological cancers in pregnancy. Lancet 2012;379:580-587.

182. Palani R, Milojkovic D, Apperley JF. Managing pregnancy in chronic myeloid leukaemia. Ann Hematol 2015;94(Suppl 2):S167-176

183. Einarson A, Maltepe C, Navioz Y, et al. The safety of ondansetron for nausea and vomiting of pregnancy: a prospective comparative study. BJOG 2004;111:940-943

184. Matok I, Gorodischer R, Koren G, et al. The safety of metoclopramide use in the first trimester of pregnancy. N Engl J Med 2009;360:2528-2535.

185. Zebrack B, Isaacson S. Psychosocial care of adolescent and young adult patients with cancer and survivors. J Clin Oncol 2012;30:1221-1226.

186. D'Agostino NM, Penney A, Zebrack B. Providing developmentally appropriate psychosocial care to adolescent and young adult cancer survivors. Cancer 2011;117:2329-2334.

187. Palmer S, Patterson P, Thompson K. A national approach to improving adolescent and young adult (AYA) oncology psychosocial care: the development of AYA-specific psychosocial assessment and care tools. Palliat Support Care 2014;12:183-188.

188. Arnett JJ. Emerging adulthood. A theory of development from the late teens through the twenties. Am Psychol 2000;55:469-480.

189. Zeltzer LK. Cancer in adolescents and young adults psychosocial aspects. Long-term survivors. Cancer 1993;71:3463-3468.

190. Evan EE, Kaufman M, Cook AB, Zeltzer LK. Sexual health and self-esteem in adolescents and young adults with cancer. Cancer 2006;107:1672-1679.

191. Ishibashi A, Okamura J, Ueda R, et al. Psychosocial strength enhancing resilience in adolescents and young adults with cancer. J Pediatr Oncol Nurs 2016;33:45-54.

192. Morgan S, Davies S, Palmer S, Plaster M. Sex, drugs, and rock 'n' roll: caring for adolescents and young adults with cancer. J Clin Oncol 2010;28:4825-4830.

193. Sleight AG, Duker LI. Toward a broader role for occupational therapy in supportive oncology care. Am J Occup Ther 2016;70:1-8

194. Stava CJ, Lopez A, Vassilopoulou-Sellin R. Health profiles of younger and older breast cancer survivors. Cancer 2006;107:1752-1759.

195. Kwak M, Zebrack BJ, Meeske KA, et al. Trajectories of psychological distress in adolescent and young adult patients with cancer: a 1-year longitudinal study. J Clin Oncol 2013;31:2160-2166.

196. Kwak M, Zebrack BJ, Meeske KA, et al. Prevalence and predictors of posttraumatic stress symptoms in adolescent and young adult cancer survivors: a 1-year follow-up study. Psychooncology 2013;22:1798-1806.

197. Zebrack BJ, Corbett V, Embry L, et al. Psychological distress and unsatisfied need for psychosocial support in adolescent and young adult cancer patients during the first year following diagnosis. Psychooncology 2014;23:1267-1275.

198. Burgoyne MJ, Bingen K, Leuck J, et al. Cancer-related distress in young adults compared to middle-aged and senior adults. J Adolesc Young Adult Oncol 2015;4:56-63.

199. Prasad PK, Hardy KK, Zhang $\mathrm{N}$, et al. Psychosocial and neurocognitive outcomes in adult survivors of adolescent and early young adult cancer: 
a report from the Childhood Cancer Survivor Study. J Clin Oncol 2015;33:2545-2552.

200. Johannsdottir IM, Karlstad O, Loge JH, et al. Prescriptions of antidepressants to survivors of cancer in childhood, adolescence, and young adulthood: a population-based study. J Adolesc Young Adult Oncol 2016.

201. Kazak AE, Derosa BW, Schwartz LA, et al. Psychological outcomes and health beliefs in adolescent and young adult survivors of childhood cancer and controls. J Clin Oncol 2010;28:2002-2007.

202. Krull KR, Huang S, Gurney JG, et al. Adolescent behavior and adult health status in childhood cancer survivors. J Cancer Surviv 2010;4:210-217.

203. Emmons K, Li FP, Whitton J, et al. Predictors of smoking initiation and cessation among childhood cancer survivors: a report from the childhood cancer survivor study. J Clin Oncol 2002;20:1608-1616.

204. Lown EA, Goldsby R, Mertens AC, et al. Alcohol consumption patterns and risk factors among childhood cancer survivors compared to siblings and general population peers. Addiction 2008;103:1139-1148.

205. Cox CL, McLaughlin RA, Steen BD, Hudson MM. Predicting and modifying substance use in childhood cancer survivors: application of a conceptual model. Oncol Nurs Forum 2006;33:51-60.

206. Rosenberg $A R$, Bona $K$, Ketterl $T$, et al. Intimacy, substance use, and communication needs during cancer therapy: a report from the "Resilience in Adolescents and Young Adults" study. J Adolesc Health 2017;60:93-99.

207. Lubman DI, Cheetham A, Yucel M. Cannabis and adolescent brain development. Pharmacol Ther 2015;148:1-16.

208. Fischer B, Russell C, Sabioni $P$, et al. Lower-risk cannabis use guidelines: a comprehensive update of evidence and recommendations. Am J Public Health 2017;107:e1-e12.

209. Zebrack B, Bleyer A, Albritton K, et al. Assessing the health care needs of adolescent and young adult cancer patients and survivors. Cancer 2006;107:2915-2923.

210. Ward EJ, Henry LM, Friend AJ, et al. Nutritional support in children and young people with cancer undergoing chemotherapy. Cochrane Database Syst Rev 2015;8:Cd003298.

211. Proserpio T, Ferrari A, Veneroni L, et al. Spiritual aspects of care for adolescents with cancer. Tumori 2014;100:130e-135e.

212. Albritton $K$, Barr $R$, Bleyer $A$. The adolescence of young adult oncology. Semin Oncol 2009;36:478-488.

213. Kyngas H, Mikkonen R, Nousiainen EM, et al. Coping with the onset of cancer: coping strategies and resources of young people with cancer. Eur J Cancer Care (Engl) 2001;10:6-11.

214. Zebrack BJ, Oeffinger KC, Hou P, Kaplan S. Advocacy skills training for young adult cancer survivors: the Young Adult Survivors Conference at Camp M $₫ \mathrm{k}$-a-Dream. Support Care Cancer 2006;14:779-782.

215. Treadgold CL, Kuperberg A. Been there, done that, wrote the blog: the choices and challenges of supporting adolescents and young adults with cancer. J Clin Oncol 2010;28:4842-4849.

216. Love B, Crook B, Thompson CM, et al. Exploring psychosocial support online: a content analysis of messages in an adolescent and young adult cancer community. Cyberpsychol Behav Soc Netw 2012;15:555-559.

217. Zebrack B. Information and service needs for young adult cancer patients. Support Care Cancer 2008;16:1353-1360.

218. Zebrack B. Information and service needs for young adult cancer survivors. Support Care Cancer 2009; 17:349-357.
219. Palmer S, Mitchell A, Thompson K, Sexton M. Unmet needs among adolescent cancer patients: a pilot study. Palliat Support Care 2007;5:127134.

220. Fallon S, Smith J, Morgan S, et al. 'Pizza, patients and points of view' Involving young people in the design of a post registration module entitled the adolescent with cancer. Nurse Educ Pract 2008;8:140-147.

221. Rabin C, Simpson N, Morrow K, Pinto B. Behavioral and psychosocial program needs of young adult cancer survivors. Qual Health Res 2011;21:796-806.

222. Kirchhoff AC, Leisenring W, Krull KR, et al. Unemployment among adult survivors of childhood cancer: a report from the childhood cancer survivor study. Med Care 2010;48:1015-1025.

223. Keegan TH, DeRouen MC, Parsons HM, et al. Impact of treatment and insurance on socioeconomic disparities in survival after adolescent and young adult Hodgkin lymphoma: a population-based study. Cancer Epidemiol Biomarkers Prev 2016;25:264-273.

224. Zeltzer LK, Recklitis C, Buchbinder D, et al. Psychological status in childhood cancer survivors: a report from the Childhood Cancer Survivor Study. J Clin Oncol 2009;27:2396-2404.

225. Martin S, Ulrich C, Munsell M, et al. Delays in cancer diagnosis in underinsured young adults and older adolescents. Oncologist 2007;12:816824.

226. Smith AW, Bellizzi KM, Keegan THM, et al. Health-related quality of life of adolescent and young adult patients with cancer in the United States: the Adolescent and Young Adult Health Outcomes and Patient Experience study. J Clin Oncol 2013;31:2136-2145.

227. Wein S, Pery S, Zer A. Role of palliative care in adolescent and young adult oncology. J Clin Oncol 2010;28:4819-4824.

228. Rosenberg AR, Wolfe J. Palliative care for adolescents and young adults with cancer. Clin Oncol Adolesc Young Adults 2013;2013:41-48.

229. Wiener L, Weaver MS, Bell CJ, Sansom-Daly UM. Threading the cloak: palliative care education for care providers of adolescents and young adults with cancer. Clin Oncol Adolesc Young Adults 2015;5:1-18.

230. Pritchard S, Cuvelier G, Harlos M, Barr R. Palliative care in adolescents and young adults with cancer. Cancer 2011;117:2323-2328.

231. Lyon ME, McCabe MA, Patel KM, D'Angelo LJ. What do adolescents want? An exploratory study regarding end-of-life decision-making. J Adolesc Health 2004;35:529 e521-526.

232. Wiener L, Zadeh S, Wexler LH, Pao M. When silence is not golden: engaging adolescents and young adults in discussions around end-of-life care choices. Pediatr Blood Cancer 2013;60:715-718.

233. Mack JW, Chen LH, Cannavale K, et al. End-of-life care intensity among adolescent and young adult patients with cancer in Kaiser Permanente Southern California. JAMA Oncol 2015;1:592-600.

234. Webb NM, Tucker D. Young adults' opinions about hospice and home death. J Palliat Med 2009;12:337-342.

235. Bell CJ, Skiles J, Pradhan K, Champion VL. End-of-life experiences in adolescents dying with cancer. Support Care Cancer 2010;18:827-835.

236. Wiener L, Ballard E, Brennan T, et al. How I wish to be remembered: the use of an advance care planning document in adolescent and young adult populations. J Palliat Med 2008;11:1309-1313. 
Adolescent and Young Adult Oncology, Version 2.2018

Individual Disclosures for Adolescent and Young Adult Oncology Panel

\begin{tabular}{|c|c|c|c|c|}
\hline Panel Member & $\begin{array}{l}\text { Clinical Research Support/Data } \\
\text { Safety Monitoring Board }\end{array}$ & $\begin{array}{l}\text { Scientific Advisory Boards, Consultant, } \\
\text { or Expert Witness }\end{array}$ & $\begin{array}{l}\text { Promotional Advisory Boards, } \\
\text { Consultant, or Speakers Bureau }\end{array}$ & Date Completed \\
\hline Lynda Beaupin, MD & None & Spectrum Pharmaceuticals & None & $7 / 6 / 17$ \\
\hline Virginia F. Borges, MD, MMSc & None & None & None & $1 / 6 / 16$ \\
\hline Scott C. Borinstein, MD, PhD & None & $\begin{array}{l}\text { Rally Foundation; and St Baldrick's } \\
\text { Pediatric Cancer Research Foundation }\end{array}$ & None & $8 / 31 / 17$ \\
\hline Rashmi Chugh, MD & $\begin{array}{l}\text { AADi, LLC; Biomarin } \\
\text { Pharmaceutical; Eli Lilly and } \\
\text { Company; Epizyme, Inc.; MabVax } \\
\text { Therapeutics, Inc.; Morphotek } \\
\text { Inc.; Novartis Pharmaceuticals } \\
\text { Corporation; and Pfizer Inc. }\end{array}$ & EMD Serono, Inc.; and Epizyme, Inc. & None & $8 / 31 / 17$ \\
\hline Peter F. Coccia, MD & None & None & None & $7 / 19 / 17$ \\
\hline Shira Dinner, MD & $\begin{array}{l}\text { Astellas Pharma US, Inc.; FLX Bio, } \\
\text { Inc.; FORMA Therapeutics; } \\
\text { Juno Therapeutics; and } \\
\text { MedImmune Inc. }\end{array}$ & None & None & $8 / 30 / 17$ \\
\hline Jeanelle Folbrecht, PhD & None & None & None & $11 / 20 / 17$ \\
\hline A. Lindsay Frazier MD, ScM & Seattle Genetics, Inc. & Seattle Genetics, Inc. & None & $2 / 6 / 17$ \\
\hline Robert Goldsby, MDa & None & None & None & $7 / 24 / 17$ \\
\hline Alexandra Gubin, MSW, LCSW-C & None & None & None & $6 / 26 / 17$ \\
\hline Robert Hayashi, MD & Otonomy, Inc. & $\begin{array}{l}\text { National Children's Cancer Society; } \\
\text { Pediatric Cancer Research Foundation; } \\
\text { and V Foundation }\end{array}$ & None & $7 / 19 / 17$ \\
\hline Mary S. Huang, MD & None & None & None & 9/13/17 \\
\hline Michael P. Link, MD & $\begin{array}{l}\text { Janssen Pharmaceutica Products, } \\
\text { LP; and Seattle Genetics, Inc. }\end{array}$ & $\begin{array}{l}\text { Array Biopharma, Inc.; Clovis } \\
\text { Oncology; Incyte Corporation; Janssen } \\
\text { Pharmaceutica Products, LP; and } \\
\text { Novartis Pharmaceuticals Corporation }\end{array}$ & $\begin{array}{l}\text { ADC Therapeutics; and } \\
\text { Kite Pharma, Inc. }\end{array}$ & $11 / 7 / 17$ \\
\hline John A. Livingston, MD & None & None & None & 9/11/17 \\
\hline Yousif Matloub, MD & $\begin{array}{l}\text { Novartis Pharmaceuticals } \\
\text { Corporation }\end{array}$ & None & None & 9/19/17 \\
\hline Frederick Millard, MD & None & Astellas Pharma US, Inc. & None & $10 / 4 / 17$ \\
\hline Kevin C. Oeffinger, MD & None & None & None & $8 / 31 / 17$ \\
\hline Alberto S. Pappo, MD & None & None & None & $7 / 4 / 17$ \\
\hline Diane Puccetti, MD & None & None & None & $8 / 8 / 17$ \\
\hline Damon Reed, MD & None & $\begin{array}{l}\text { Janssen Pharmaceutica Products, LP; } \\
\text { and Shire Pharmaceuticals }\end{array}$ & None & $7 / 10 / 17$ \\
\hline Steven Robinson, MBBS & None & None & None & $3 / 22 / 17$ \\
\hline Abby R. Rosenberg, MD, MS & None & None & None & $9 / 7 / 17$ \\
\hline Tara Sanft, MD & None & None & Biotheranostics & $8 / 7 / 17$ \\
\hline Holly L. Spraker-PerIman, MD, MS & None & None & None & $9 / 26 / 17$ \\
\hline Margaret von Mehren, MD & $\begin{array}{l}\text { Arog Pharmaceuticals, Inc.; } \\
\text { Arqule, Inc.; Blueprint Medicines } \\
\text { Corporation; CytRx Corporation; } \\
\text { Immune Design; Karyopharm } \\
\text { Therapeutics Inc.; and SARC }\end{array}$ & $\begin{array}{l}\text { Deciphera Pharmaceuticals, Inc.; and } \\
\text { Janssen Pharmaceutica Products, LP }\end{array}$ & None & $3 / 25 / 17$ \\
\hline Daniel S. Wechsler, MD, PhD & Karyopharm Therapeutics Inc. & $\begin{array}{l}\text { Hyundai Hope on Wheels; Pablove } \\
\text { Foundation; and St. Baldrick's } \\
\text { Foundation }\end{array}$ & None & $3 / 7 / 17$ \\
\hline Kimberly F. Whelan, MD & None & None & None & $2 / 7 / 17$ \\
\hline Nicholas Yeager, MD & None & None & None & $8 / 21 / 17$ \\
\hline
\end{tabular}

The NCCN Guidelines Staff have no conflicts to disclose.

aThe following individuals have disclosed that they have an Employment/ Governing Board, Patent, Equity, or Royalty conflict:

Robert Goldsby, MD: Pfizer Inc.

Daniel S. Wechsler, MD, PhD: American Board of Pediatrics; Subboard on Pediatric Hematology Oncology; American Society of Pediatric

Hematology; and Oncology Board of Trustees 